\title{
The State of Chemical Modeling Modules for the Degradation of Concrete and Cements
}

Annemarie Meike, Editor

April 15, 1997

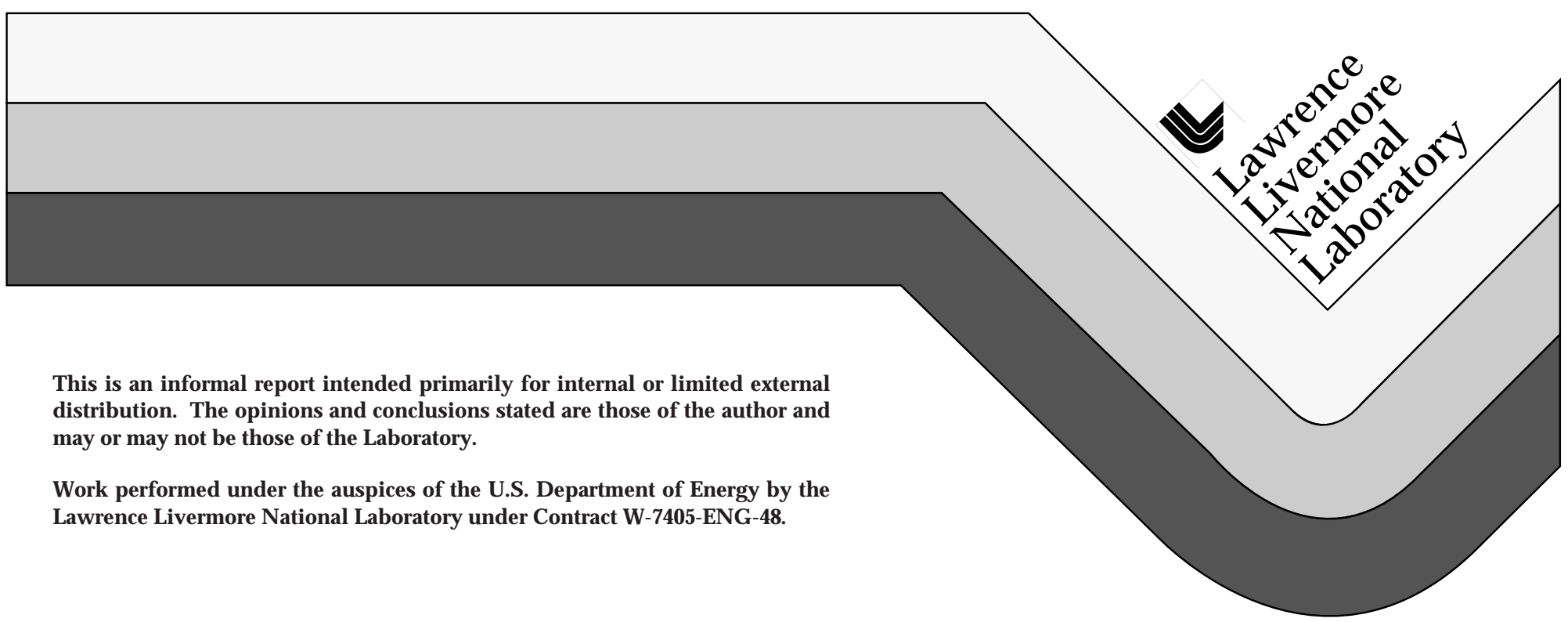




\section{DISCLAIMER}

This document was prepared as an account of work sponsored by an agency of the United States Government. Neither the United States Government nor the University of California nor any of their employees, makes any warranty, express or implied, or assumes any legal liability or responsibility for the accuracy, completeness, or usefulness of any information, apparatus, product, or process disclosed, or represents that its use would not infringe privately owned rights. Reference herein to any specific commercial product, process, or service by trade name, trademark, manufacturer, or otherwise, does not necessarily constitute or imply its endorsement, recommendation, or favoring by the United States Government or the University of California. The views and opinions of authors expressed herein do not necessarily state or reflect those of the United States Government or the University of California, and shall not be used for advertising or product endorsement purposes.

This report has been reproduced directly from the best available copy.

Available to DOE and DOE contractors from the Office of Scientific and Technical Information P.O. Box 62, Oak Ridge, TN 37831

Prices available from (615) 576-8401, FTS 626-8401

Available to the public from the National Technical Information Service

U.S. Department of Commerce 5285 Port Royal Rd.,

Springfield, VA 22161 


\title{
The State of Chemical Modeling Modules for the Degradation of Concrete and Cements
}

\author{
Annemarie Meike, Editor \\ Contributing Authors \\ A. Meike \\ C. Seibel \\ L. Clodic \\ B. Bourcier \\ P. A. Sterne
}

April 15, 1997 



\section{Contents}

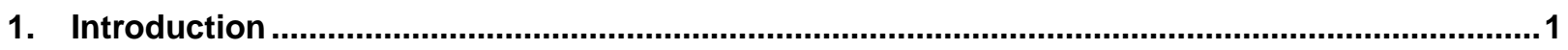

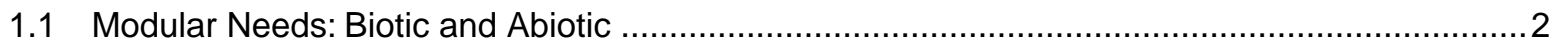

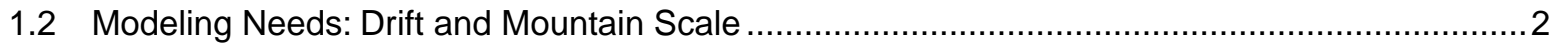

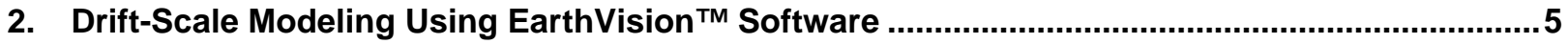

3. The Module Concept: Developing the Capability to Model Complex Chemical Scenarios ......21

3.1 The Explorer ${ }^{\mathrm{TM}}$ Modular Modeling Environment ............................................................21

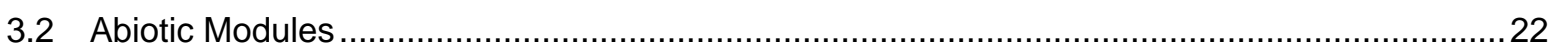

3.2.1 The EQ3NR/EQ6 Modeling Code and Associated Databases ..................................22

3.2.2 Systems Containing Cementitious Materials............................................................. 24

3.2.3 Evaluating Common Minerals in the $\mathrm{Ca}-\mathrm{Si}-\mathrm{CO}_{2}-\mathrm{H}_{2} \mathrm{O}$ System ..................................25

3.2.4 Chemical Modeling of Available Crystalline $\mathrm{Ca}-\mathrm{Si}-\mathrm{Hydrate}$ Phases

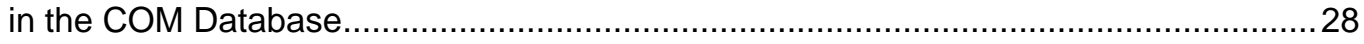

3.2.5 Developing New Databases that Contain Ca-Si-Hydrate Phases ...............................29

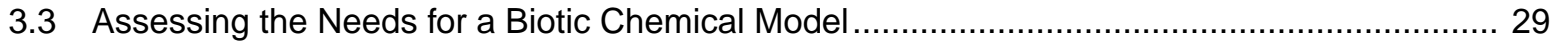

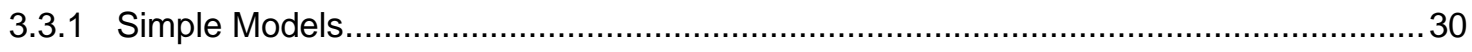

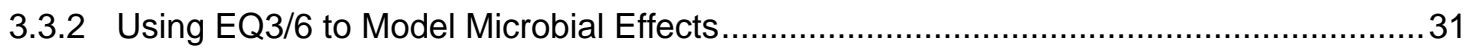

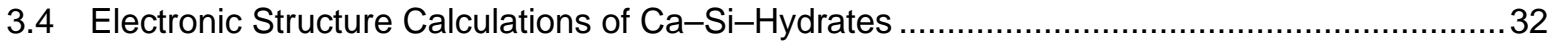

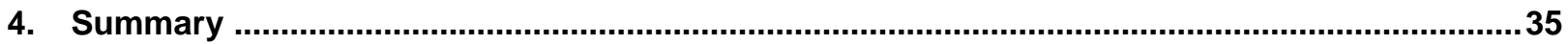

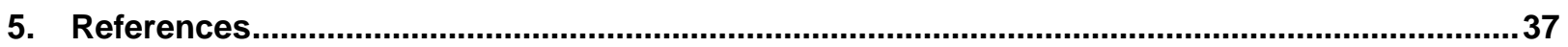

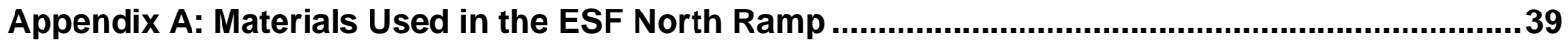





\section{Introduction}

If Yucca Mountain is recommended as a site for a proposed high-level waste repository, a license application (LA) will be submitted to the Nuclear Regulatory Commission (NRC) in few years. As part of this application process, we must better understand the long-term chemical implications of introducing natural and fabricated materials as well as microbes into a radioactive waste repository. Some of these materials would be introduced during construction; others would be introduced passively, even unintentionally. For those materials that are explicitly chosen for construction, we may be able to substitute alternates if suitable replacements can be found. Other materials may not be interchangeable. Thus, the advantages and disadvantages of using various materials are being considered by groups working on repository design and performance assessment.

The goal of the Introduced Materials Task is to identify explicitly the materials that may be introduced, intentionally or unintentionally, and to provide sound science to support decisions regarding the use or restriction of those materials. Our purpose is to identify the chemical modifications that mark significant deviations from the natural environment and that thus may render predictions of repository performance based on the natural environment less than complete. We intend to refine and narrow chemical bounding conditions related to materials that are at present not well defined for the durations and conditions of interest and, thus, improve the ability to demonstrate the potential effects of these materials on the repository lifetime. This work will support the determination of importance evaluations (DIE), the performance assessment (PA), and the repository design decisions to include information on restricting and substituting materials on the basis of sound scientific and economic grounds.

The initial concepts regarding materials and construction effects were obtained from the literature (West, 1978), from an assessment of the materials and methods used to construct the Exploratory
Studies Facility (ESF) (see Meike and Spragge, 1995), and from an analysis of historical analogs (see Meike and Spragge, 1995; Bruton et al., 1995; Rogers, 1995). From this information, we quantified and evaluated the chemical implications of materials, determined accessory materials that are implied by repository design, and defined suites of materials by design function. This work is fundamental to establishing the initial post-closure environment.

There are three reasons for using modeling to understand the chemical modifications of the natural environment in a repository setting. First, the chemical consequences of some of these materials are not common to our experience for the long time periods nor for the conditions of an underground radioactive waste repository. Computer modeling using fundamental chemical principles allows us to project chemical conditions far into the future and to examine the system from selected points in time. Second, modeling can significantly reduce the number of experimental trials required to demonstrate a similar understanding of chemical processes. Modeling chemical processes is economical and efficient both for simulating long time periods and for investigating the consequences of multiple combinations of materials. Third, modeling provides the flexibility required to support repository design and performance assessment at a stage where multiple options are being considered.

Modeling is effective-not as an end in itself, nor as a tool to be used independently of other efforts-but rather as one facet of a program that is coordinated with experimental and historic analog activities. Such a coordinated program on a small scale is demonstrated in a progress report on the long-term chemical impact of diesel exhaust (Meike et al., 1994a). In that report, the modeling program is reviewed with respect to the development of modeling capability in the area of cementitious materials (ordinary Portland cement, grouts, and concretes) because the work in this area is more advanced than that for other materials. The cement work has been supported primarily by the 
International Program of the Office of Civilian Radioactive Waste Management (OCRWM) with the intention that work would continue under the auspices of the Introduced Materials Task. However, the following report demonstrates modeling considerations and the progression of modeling steps that will be required for all materials.

The strategy of the Introduced Materials Task is focused in two areas. First, we are developing material-specific modules that can be operated independently or can be interconnected to simulate design and construction options under consideration (Sections 1.1 and 3). Second, but concurrently to the first, we are developing the capability to simulate and visualize chemical processes in three dimensions within the geologic context of Yucca Mountain (Sections 1.2 and 2).

\subsection{Modular Needs: Biotic and Abiotic}

The most important role of the material-specific chemical module is to reflect a material's chemical significance in a streamlined manner. Thus, if the module can demonstrate that a material has no effect on the chemical environment, then the material can be eliminated from modeling that scenario. More realistically, if the module can demonstrate that a material is involved to a significant extent in only certain chemical processes, then computer simulation is needed only for those processes. Of course, the modules are only as robust as their foundations; thus, the chemical role that any material plays must be examined carefully across the range of changing parameters to assure that assumptions have not been overly simplistic. If done correctly, the modular approach can streamline the computer modeling significantly without affecting the capability to comment on questions that are significant to repository design.

At present, our chemical modeling strengths lie in the ability to model the abiotic geologic system over long periods and a range of temperature and chemical conditions using aqueous geochemical modeling packages such as EQ3/6. This code is based on fundamental chemical principles and, thus, should be adaptable to any materials. However, adapting this code to simulate the long-term chemical degradation of nontraditional geologic materials involves two considerations: (1) signifi- cant chemical processes must be represented adequately, and (2) data for the appropriate phases must be represented in material-specific databases that support the modeling packages. The database requirements are described in detail in Section 3.2, with respect to cement. In the process, we hope that some general considerations involving the databases will become clear.

Two aspects of chemical processes also must be considered. First are those processes that have not yet been included in the code: abiotic processes, such as redox, which are fundamentally important to modeling metal degradation (this research is being developed within the Geochemical Modeling Task). Second are those processes that were not intended to be part of the code. These include all biotic processes, specifically the chemical consequences of microbial activity.

Modeling the chemical effects of biotic processes in a repository is a more demanding problem than those that traditional geologic models were designed to solve. Abiotic chemistry seems to adequately describe the rates and results of chemical processes in systems of traditional geologic interest. However, in a radioactive waste repository, the abiotic chemistry is only one part of the chemical needs. In a natural system-even in the deep subsurface-microbes are bound to be present (native and introduced), and many of the materials that may be introduced into a radioactive waste repository may provide nutrient sources to initiate microbial blooms (Horn and Meike, 1995). Thus, in the rest of this chapter, we examine the state of abiotic and biotic modeling, primarily in terms of the requirements for modeling cement.

The material specific modules as well as the abiotic and biotic codes will be linked together via a modeling environment called Explorer ${ }^{\mathrm{TM}}$. The capabilities of this modeling environment are also in the initial stages of being tested.

\subsection{Modeling Needs: Drift and Mountain Scale}

The needs of the Yucca Mountain Project as defined in the Nuclear Waste Policy Act of 1982 (NWPA, 1983) as amended (Dec. 22, 1987) PL100203, Section 135(a) of 10 CFR Part 60 (NRC, 1988), and 10 CFR 60 (NRC, 1990) push science and technology to 
the edges of present capabilities. In modeling, this is certainly true, especially when the goal is to examine the effects of multiple complex processes at different scales. Therefore, the Introduced Materials Task has initiated work in three-dimensional modeling. We chose a three-dimensional modeling software that can integrate a range of material properties (chemical, hydrological, and mechanical), and that is established as a platform for modeling geologic processes. We plan to work from drift scale to repository scale, and ultimately, to mountain scale, progressively establishing those spatial and temporal characteristics that must be transferred to the next larger scale. Thus, we did not choose a software program that provided ease in initial rendering of the engineered features. Rather, we worked closely with Dynamic Graphics, Inc., to explore the limits of a geologic modeling program called EarthVision $^{\mathrm{TM}}$ in its ability to render engineering details. The initial efforts toward drift-scale, three-dimensional modeling are discussed in Chapter 2. 


\section{Drift-Scale Modeling Using EarthVision ${ }^{\mathrm{TM}}$ Software}

In this study, we wanted to determine whether repository design features could be represented within the EarthVision ${ }^{\mathrm{TM}}$ software modeling framework. EarthVision ${ }^{\mathrm{TM}}$ software was developed by Dynamic Graphics, Inc., for geologic modeling applications. It has been used elsewhere in the Yucca Mountain Project to visualize the structural geology of Yucca Mountain and the excavated block from Fran Ridge, which was designated for the Large Block Test. By using this package, we increase the potential of efficiently interfacing with other Yucca Mountain Project activities.

EarthVision $^{\mathrm{TM}}$ is not a simple computergenerated architectural design (CAD) program. In fact, developing the visual display for drift scale features was much less straightforward than might be immediately apparent. The various features shown in these models were produced by routines that were originally formulated to produce geologic features. Therefore, all of the physical features were produced by combinations of faulting, deposition, erosion, and drilling.

Certainly, the work that went into producing these three-dimensional representations of potential repository designs would not be worthwhile if they were intended as only graphical representations. However, once built, the potential benefits are great. Our goal is to use these representations for drift-, repository-, and mountain-scale hydrological and chemical modeling. With EarthVision ${ }^{\mathrm{TM}}$, we can assign physical attributes to the various forms; thus, these attributes can be used to visualize the predicted evolution of the repository based on input from complex chemical, hydrological, and coupled chemical-hydrological models. We also can use it to locate materials, calculate volumes with ease, and locate the interfaces between materials (to highlight sites of a specified chemical reaction).

EarthVision $^{\mathrm{TM}}$ software has two potential advantages; it allows us to: (1) use existing Nevada State Survey coordinate data to interface with existing geochemical and hydrogeological models, and (2) develop an interactive approach between drift, repository, and mountain scales to address hydrolog- ical and chemical questions. We expect that the first use of this software will be in support of drift-scale hydrological and chemical modeling, using the chemical formulations for grout and steel that have been provided by the Yucca Mountain Project (Appendix A).

This exercise has explored the limits of the EarthVision ${ }^{\mathrm{TM}}$ software in several ways with satisfactory results. The figures in this chapter demonstrate the software's capabilities. In Figure 1, a repository layout that is being considered is plotted using Nevada State Survey coordinate grid references, so that it can be easily placed into any other EarthVision $^{\mathrm{TM}}$ representation of Yucca Mountain processes. The actual relative sizes of main and emplacement drifts are shown. We demonstrated a level of detail sufficient to use modeling to help solve major hydrological and chemical questions concerning repository construction.

Figures 2 and 3 illustrate various aspects of the emplacement tunnel. The cutaway view of the tunnel shows how EarthVision ${ }^{\mathrm{TM}}$ can represent discontinuous shapes (Figure 2). We found that waste packages were more easily modeled with rounded ends. Although the depiction in this case is for computational simplicity, the shape may have some merits for structural integrity. Figure 3 is illustrated to scale: a $25-\mathrm{m}$ section of a 4.3-m-diam emplacement tunnel, with concrete invert, gantry tracks, and concrete waste package supports.

Figures 4 through 6 show various aspects of the service tunnel. The simplified cross-section rendering of a 20-m section of the main 7.6-m-diam service tunnel (Figure 4) shows concrete invert, shotcrete layer, and rock bolts for the metal grate platform anchored into the surrounding rock. The metal platform supports are placed at about 2-m intervals. A similar length of exposed service tunnel (Figure 5) demonstrates the level of detail that can be obtained for chemical and hydrological modeling at the scale of tens of meters. The cementitious materials, concrete invert, and shotcrete are illustrated. The metal materials illustrated are the 
gantry car rails, platform supports, platform, and platform anchor rock bolts.

Figures 6 through 10 illustrate the rock-support rock bolts. The oblique view of the service tunnel (Figure 6) illustrates rock-bolt holes. Given standard spacing $(1.5 \mathrm{~m})$ as depicted on engineering drawings, 104 rock bolts would be used in a tunnel this long. A cross-sectional rendering (Figure 7) and a cutaway view (Figure 8) show the rock-bolt holes for the main 7.6-m-diam service tunnel. Figures 9 and 10 show the cross-sectional rendering and cutaway view of a $20-\mathrm{m}$ section of emplacement tunnel; given the standard spacing $(1.5 \mathrm{~m})$ as depicted on engineering drawings, 36 rock bolts would be needed for a tunnel this long. Using these visual and calculational tools, we can examine the chemical and hydrological effects of a plume of fluids equilibrated with cement (e.g., elevated $\mathrm{pH}$ ) moving into the mountain. Also, the orientation and spacing of rock bolts can clearly influence hydrology. Using EarthVision ${ }^{\mathrm{TM}}$ software, we can examine how rock bolts influence hydrology at different scales, from single drifts, to the repository, and finally, to the entire mountain.

Because of its level of detail, EarthVision ${ }^{\mathrm{TM}}$ also can display individual rock bolts with grout (Figures 11,12), and it can model finite objects (Figures $13,14)$. Calculating material volumes is a straightforward procedure, as illustrated in Figures 13 and 14. Figure 13 shows the volume of cementitious materials calculated for a a 20-m section of 4.3-m-diam emplacement drift (approximately $54.1 \mathrm{~m}^{3}$ ), and Figure 14 shows the volume of metallic materials calculated for the same section (approximately $14.4 \mathrm{~m}^{3}$ including the waste packages, which have a wall thickness of about $0.2 \mathrm{~m}$ ). The visualization can be easily modified or new ones constructed to simulate design concepts as they evolve. For example, rock bolts, or other elements, can be shortened or lengthened or added or even eliminated, as required by the design.

Earth Vision ${ }^{\mathrm{TM}}$ has proven to be an admirable platform for the visual display of complex data over a range of scales (i.e., mountain, repository, drift, and the multiple material components of a single rock bolt). Thus, the potential exists to interface chemical modeling on all of these scales. The ability to link physical and chemical parameters with location and time will ultimately allow us to display these processes in time lapse sequences. However, even at this initial phase, the benefit of three-dimensional visualization, for example the potential impact of rock-bolt placement on hydrology, is immediately clear.

Concurrent with developing the capability to display the results of our modeling efforts within a three-dimensional geological context, we also foresee the need to couple multiple codes that operate on varying levels of complexity to describe specific scenarios. For example, at the drift scale, scenariospecific modeling is more efficient in terms of computational time. To do this, we must be able to link smaller material- and process-specific models into a modular environment. Explorer ${ }^{\mathrm{TM}}$ is the software with which we will do this work; it is described in the Section 3.1. 


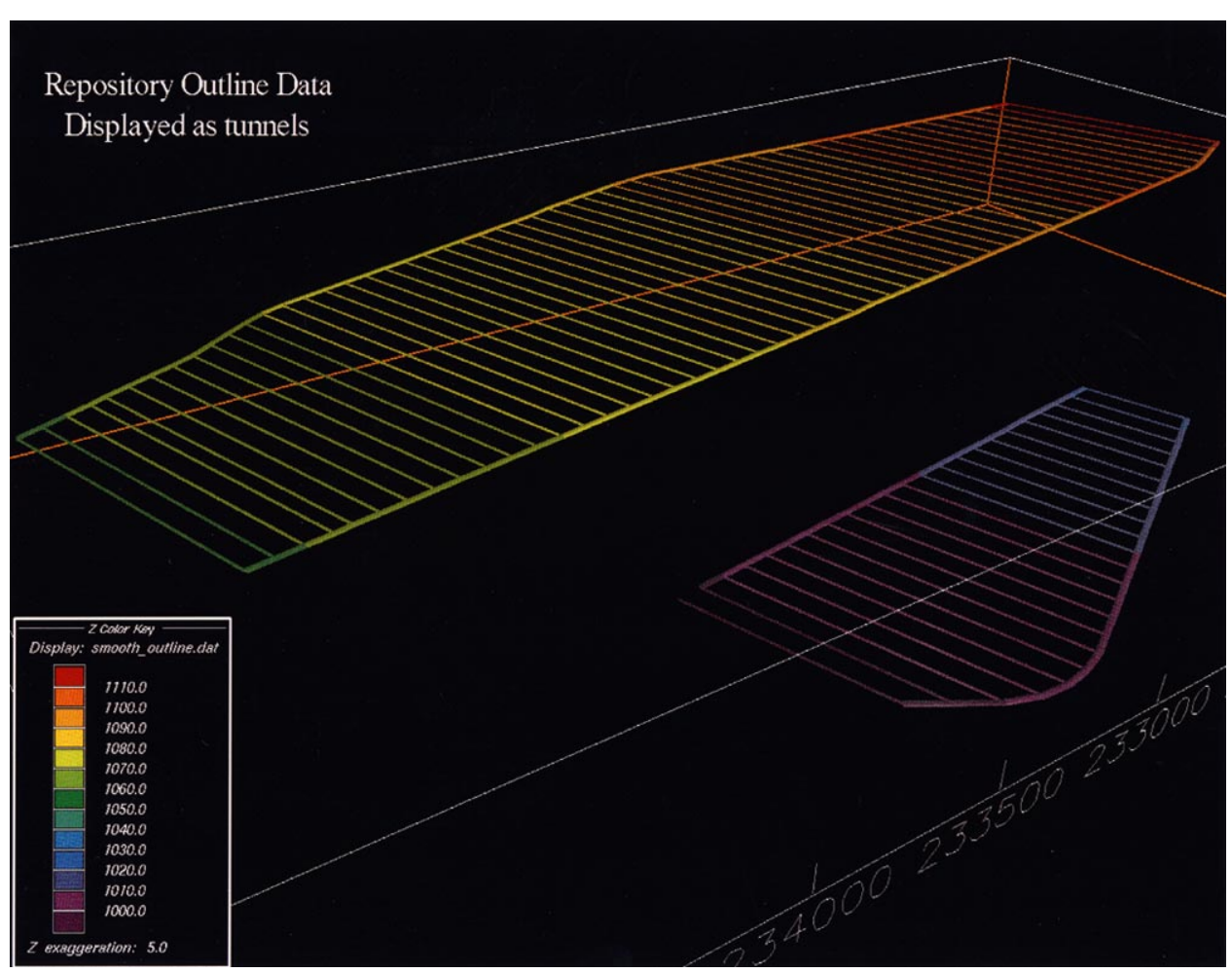

Figure 1. Proposed emplacement tunnel footprint illustrated using the Nevada State Survey coordinate grid, which will allow us to easily integrate existing Yucca Mountain geologic data. Relative sizes of main and emplacement drifts are shown. Colors relate to elevation (see legend).

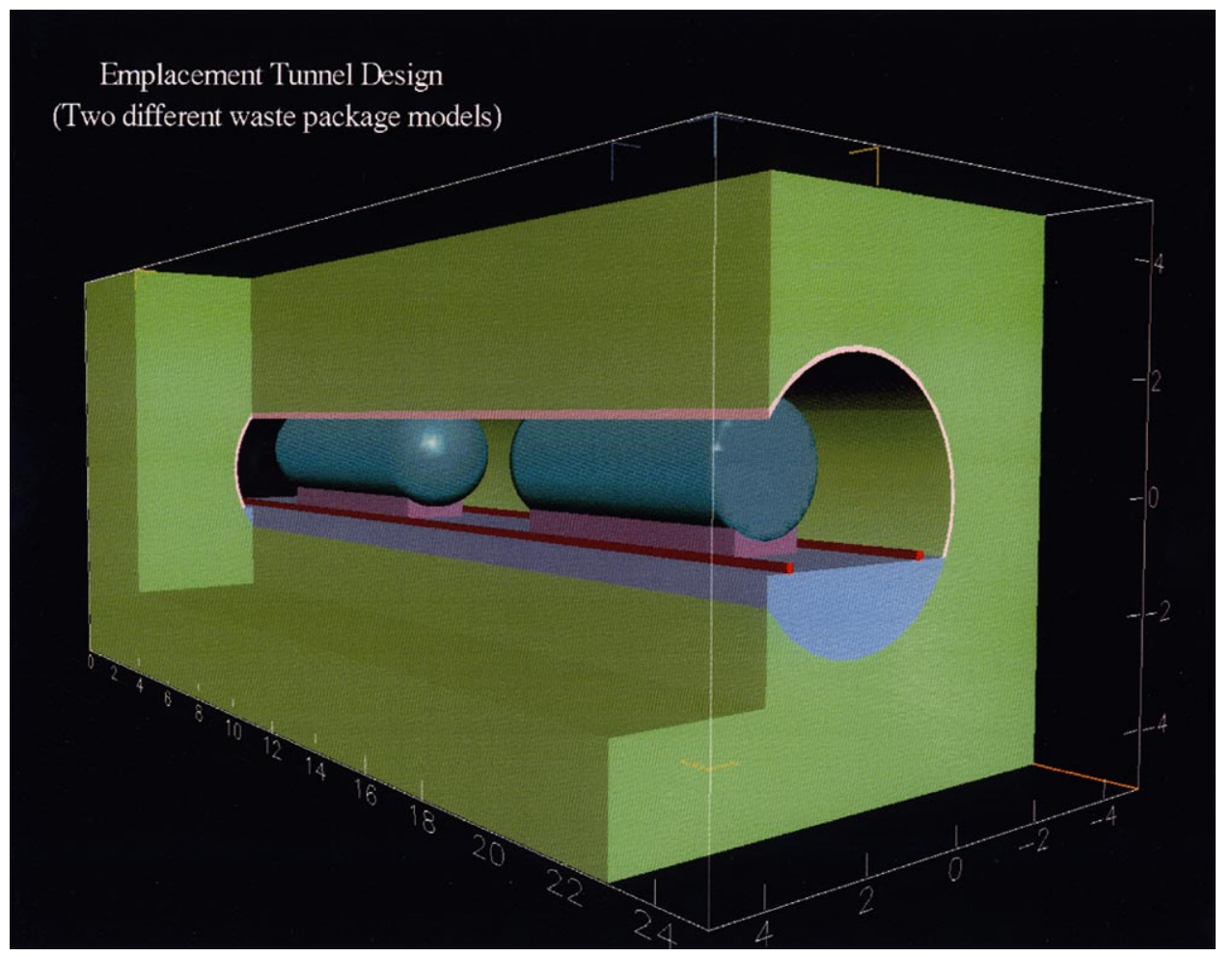

Figure 2. Cutaway view of the emplacement tunnel, showing how EarthVision software represents discontinuous shapes (scale bar in meters). In this simplified model, waste packages (blue; $6 \mathrm{~m} \times 0.2$ $\mathrm{m}$ diam), cementitious materials (pink and lavender), and gantry tracks (red) are installed in the surrounding rock (green). The waste packages were more easily modeled with rounded ends, but the shape may also have structural merits. 


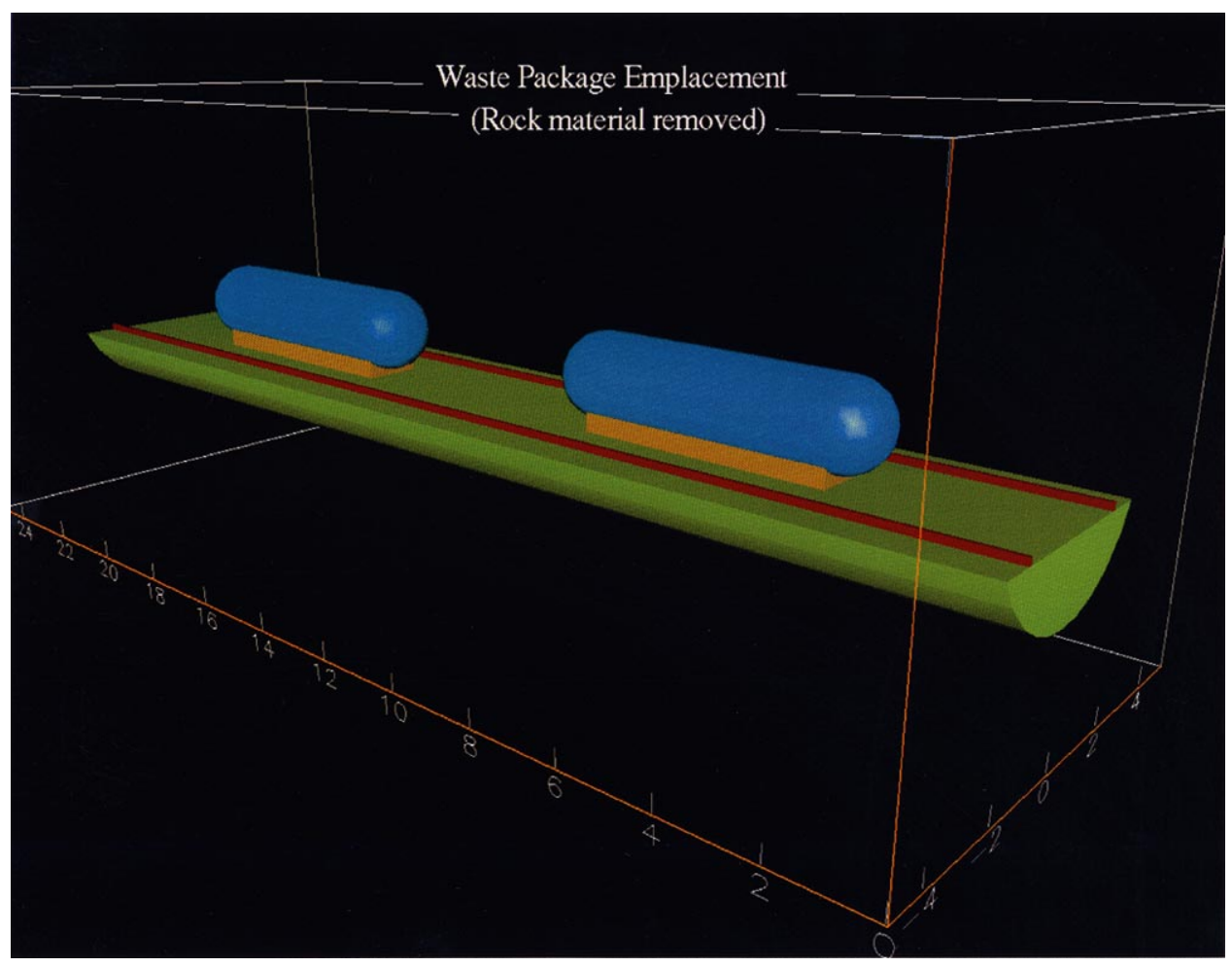

Figure 3. A $25-\mathrm{m} \mathrm{sec}-$ tion of 4.3-m diamemplacement tunnel (scale bar in meters). Waste packages (blue; $6.5 \times 1.75 \mathrm{~m}$ diam) are depicted with rounded ends for computational simplicity. Concrete invert (green; about $1.5 \mathrm{~m} \times 4 \mathrm{~m})$, gantry tracks (red; about $3.5 \mathrm{~m}$ between tracks), and concrete waste package supports (gold; $5.3 \mathrm{~m}$ in length) are shown to scale.

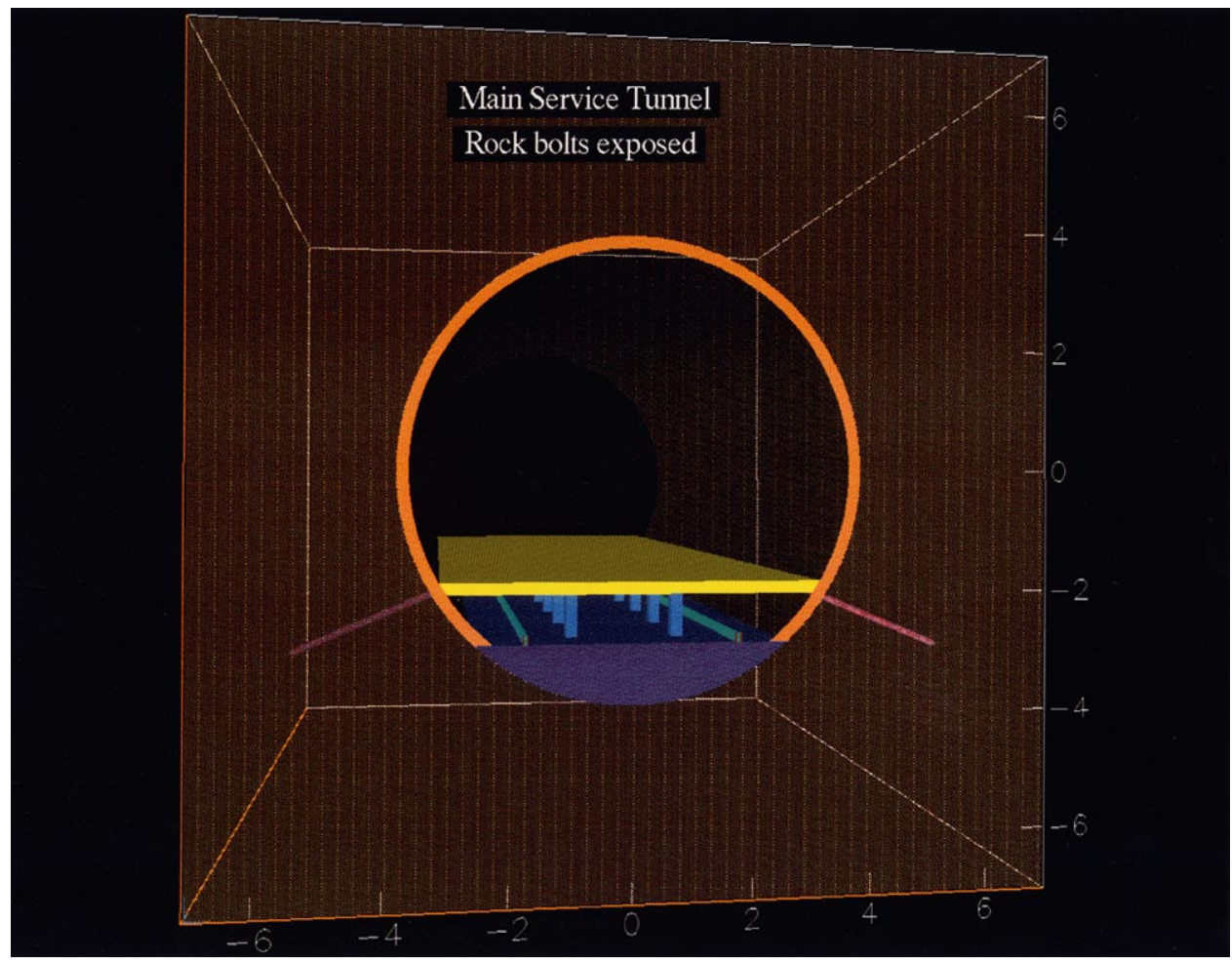

Figure 4. Simplified cross section of a 20-m section of 7.6-m diam service tunnel (scale bar in meters), showing rock bolts (pink; about $3 \mathrm{~m}$ long and $0.10 \mathrm{~m}$ in diam) for the metal grate platform (yellow; about $0.2 \mathrm{~m}$ thick) anchored into the surrounding rock (brown). The metal platform supports (light blue; about $0.2 \times 0.3 \times 1.0 \mathrm{~m}$ ) are placed at 2-m intervals. A concrete invert (purple; about $1.5 \mathrm{~m}$ ) and shotcrete layer (gold; $0.2 \mathrm{~m}$ thick) are shown. 


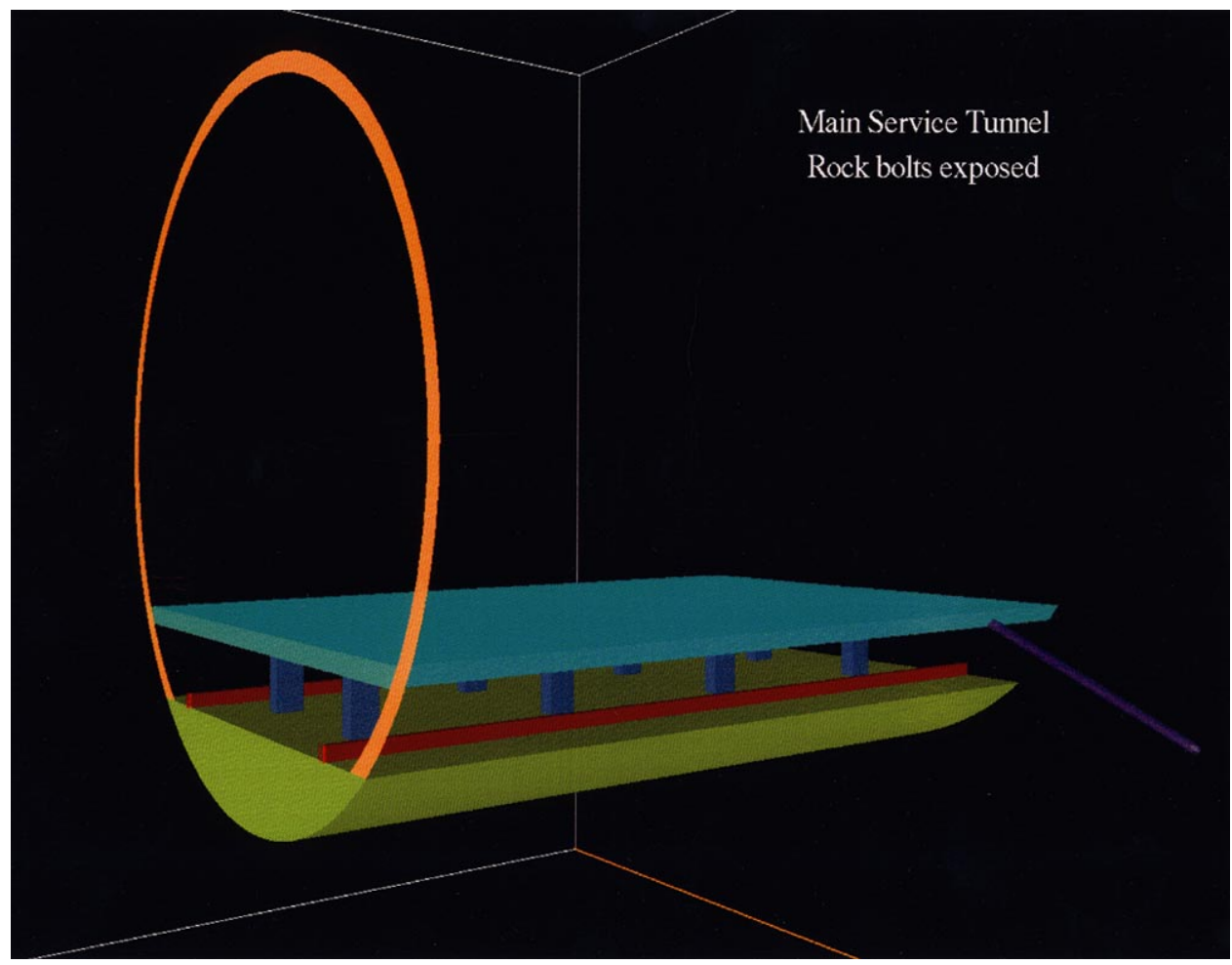

Figure 5. Exposed 20$m$ section of the main, 7.6-m-diam service tunnel (scale bar in meters), showing the detail that can be obtained for chemical and hydrological modeling at a scale of tens of meters. The cementitious materials shown are concrete invert (green) and shotcrete (gold); metal materials are gantry car rails (turquoise), platform supports (blue), platform (yellow), and platform anchor rock bolts. Figures 6-10 show rock-support rock bolts.

Oblique View of Main Service Tunnel

20 meter long tunnel section with 104 rock bolt holes

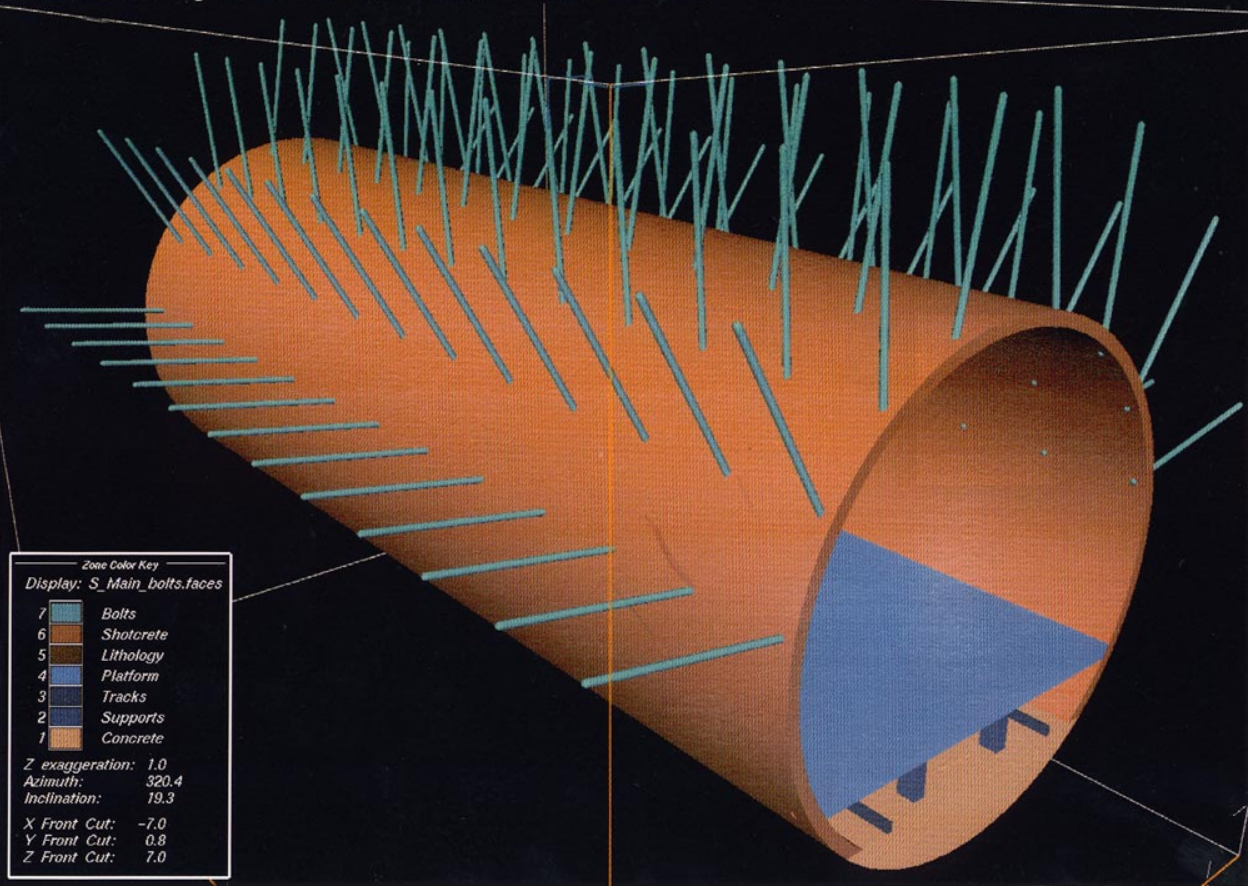

Figure 6. Oblique view of a $20-\mathrm{m}$ section of the main, 7.6-m-diam service tunnel showing rockbolt holes. Given standard spacing (1.5 $\mathrm{m})$ as depicted on engineering drawings, 104 rock bolts would be found in a tunnel this long. 


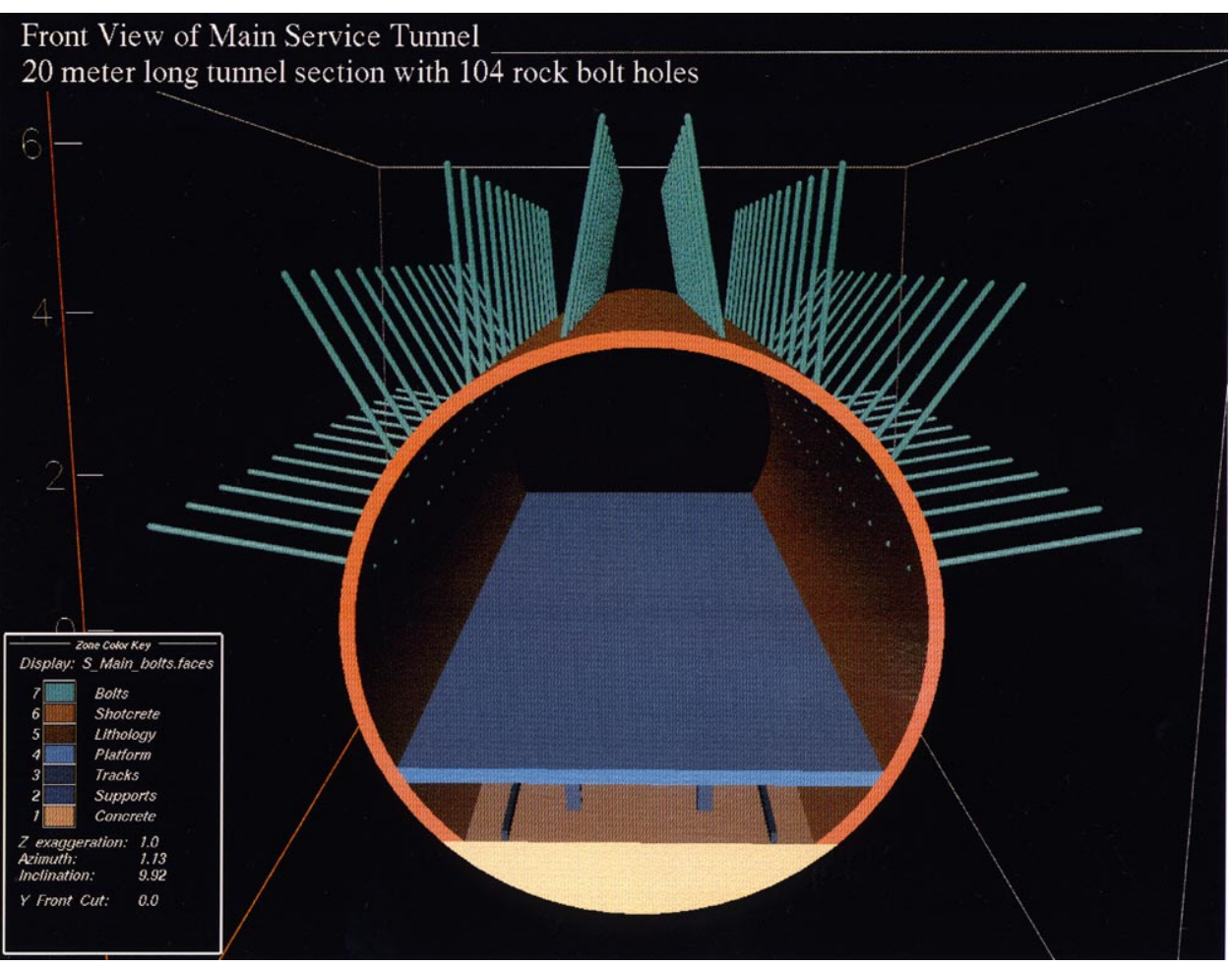

Figure 7. Cross section of a $20-\mathrm{m}$ section of the main, 7.6-mdiam service tunnel showing rock-bolt holes.

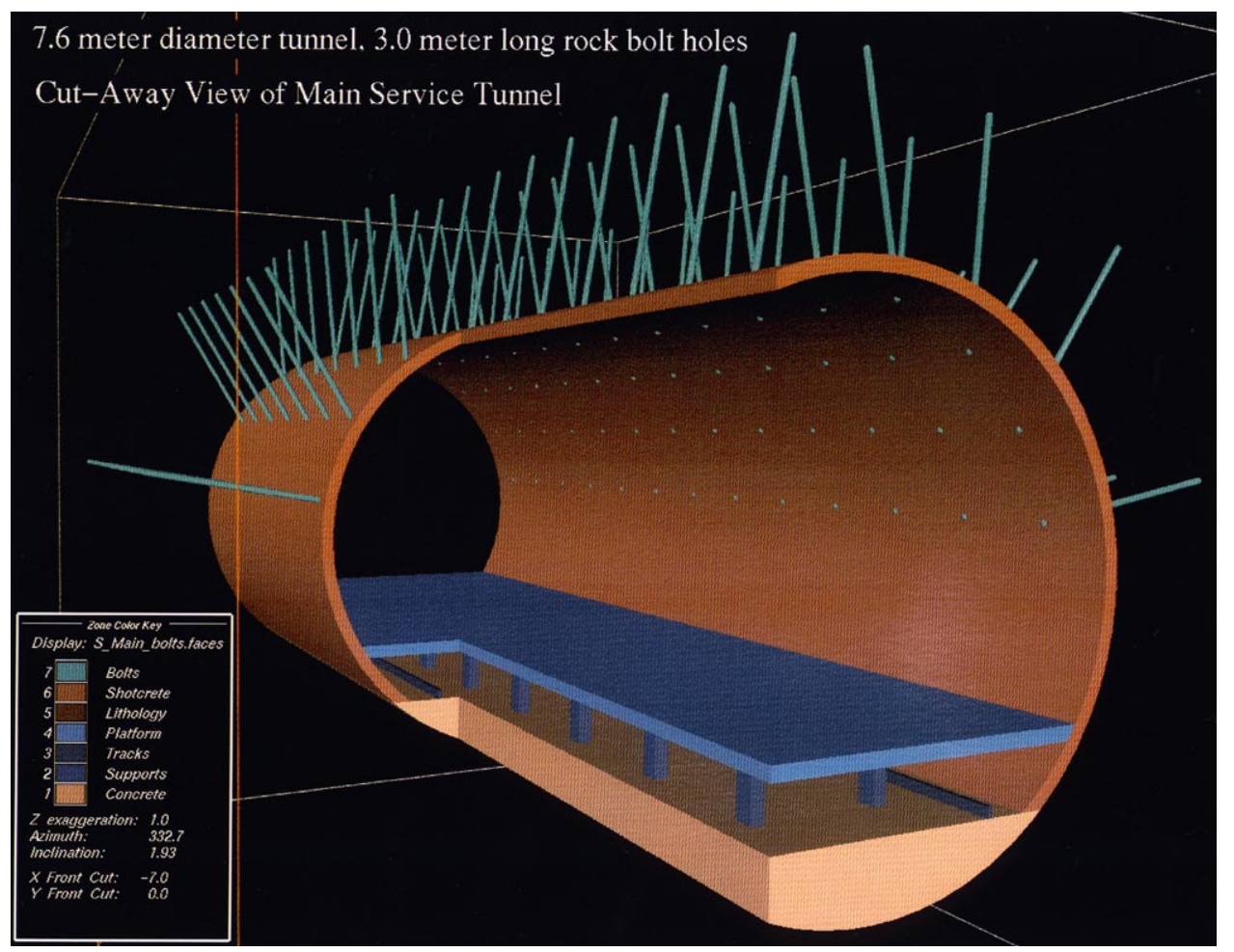

Figure 8. Cutaway view of a $20-\mathrm{m}$ section of the main, 7.6-m-diam service tunnel showing rockbolt holes. 


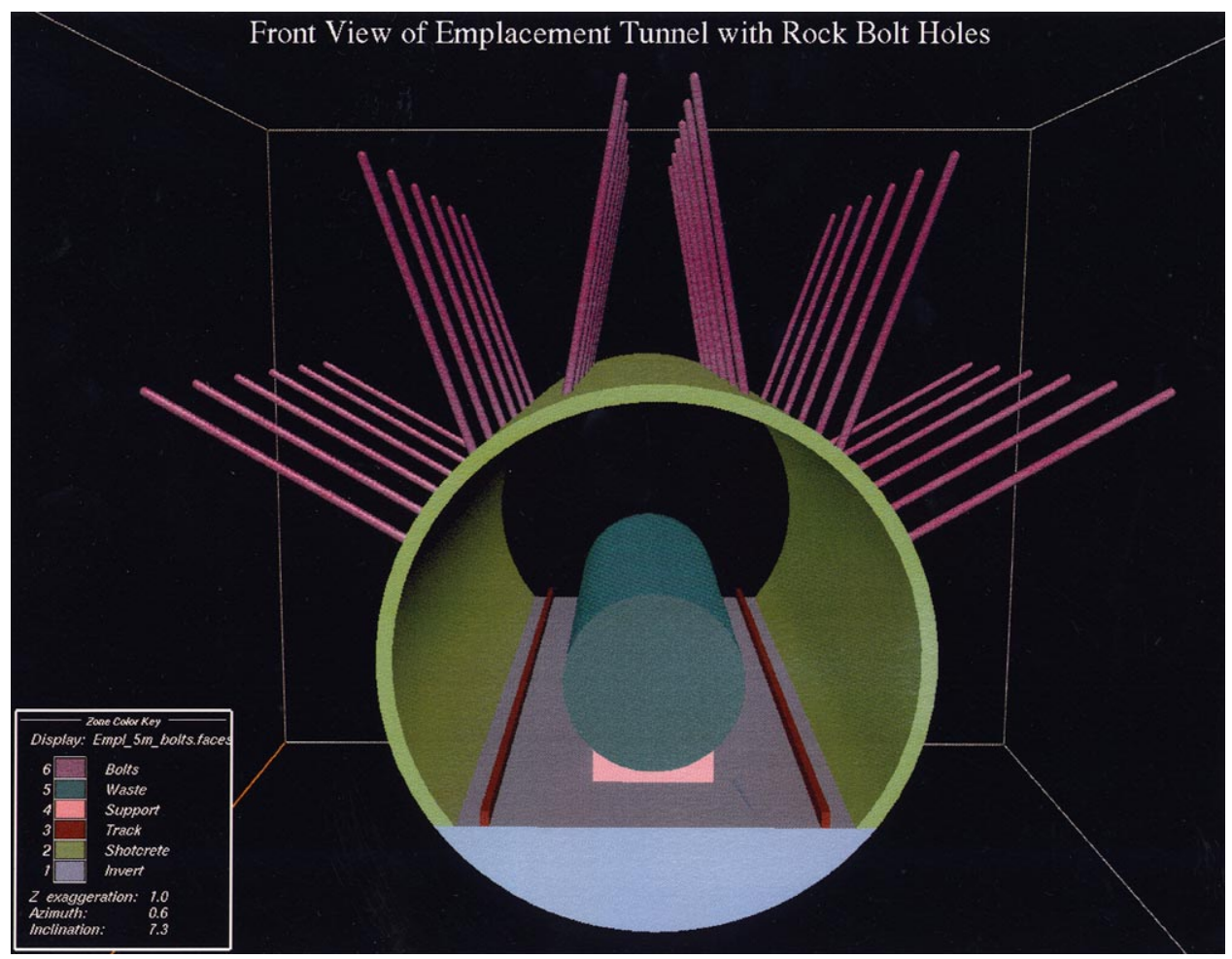

Figure 9. Cross section of a $20-\mathrm{m}$ section of a 5.0-m-diam emplacement tunnel showing rock-bolt holes. Given standard spacing $(1.5 \mathrm{~m})$ as depicted on engineering drawings, 36 rock bolts would be found in a tunnel this long.

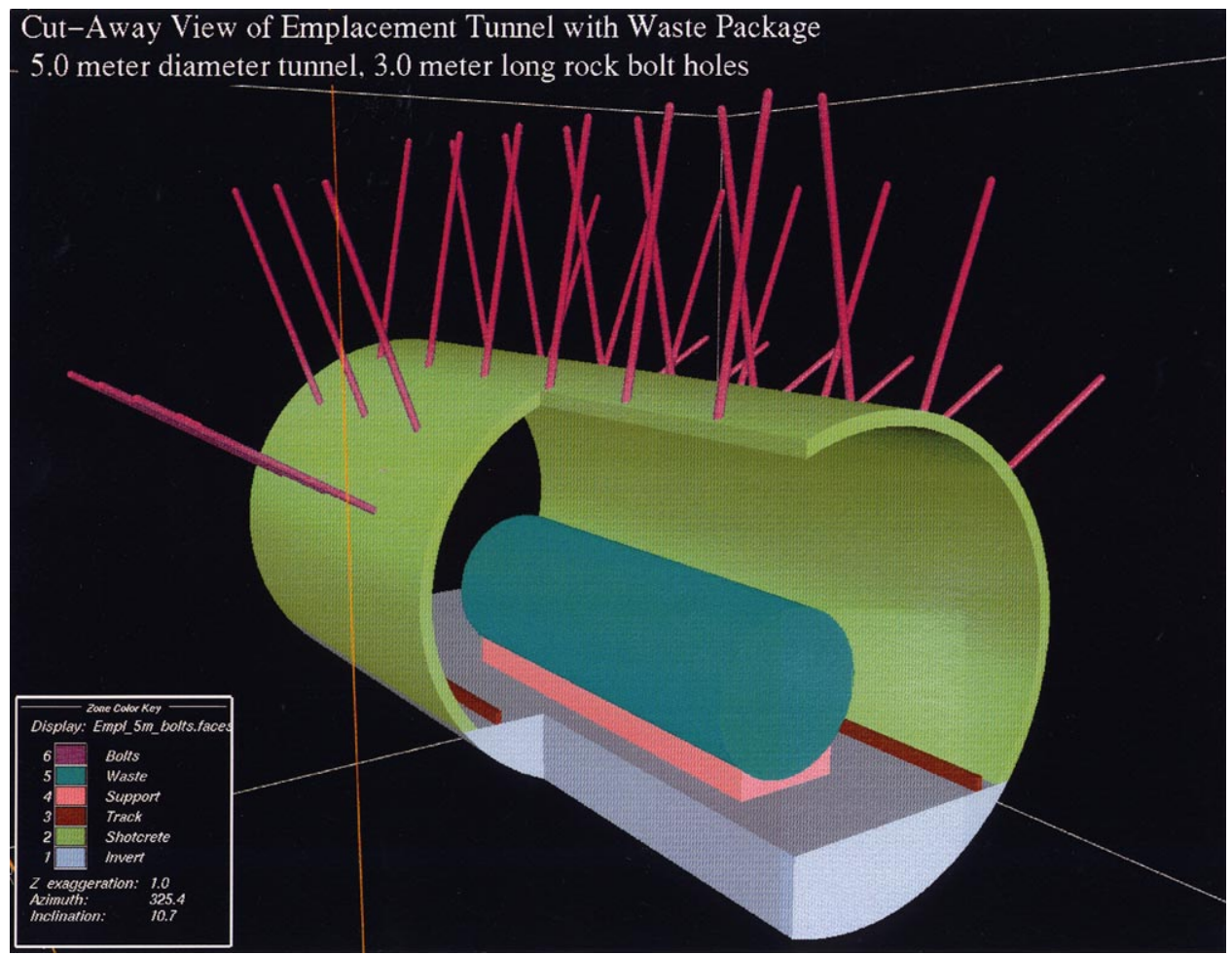

Figure 10. Cutaway view of a $20-\mathrm{m} \mathrm{sec}-$ tion of a 5.0-m-diam service tunnel showing rock-bolt holes. 

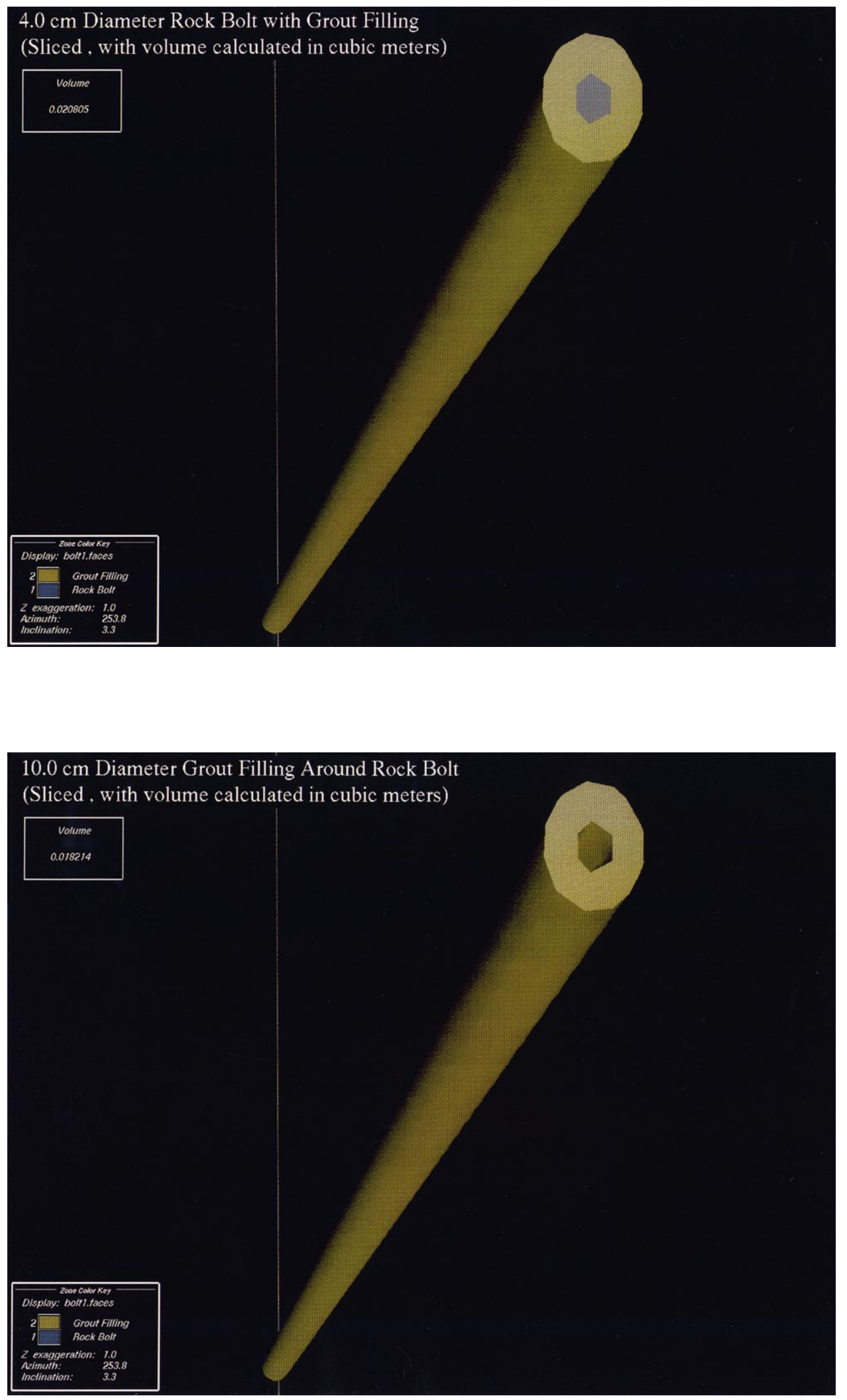

Figure 11. Rockbolt detail showing steel rock bolt (gray) and exterior grout filling.
Figure 12. Calculational detail of the volume of grout (0.018214 m) used for one rock bolt. 


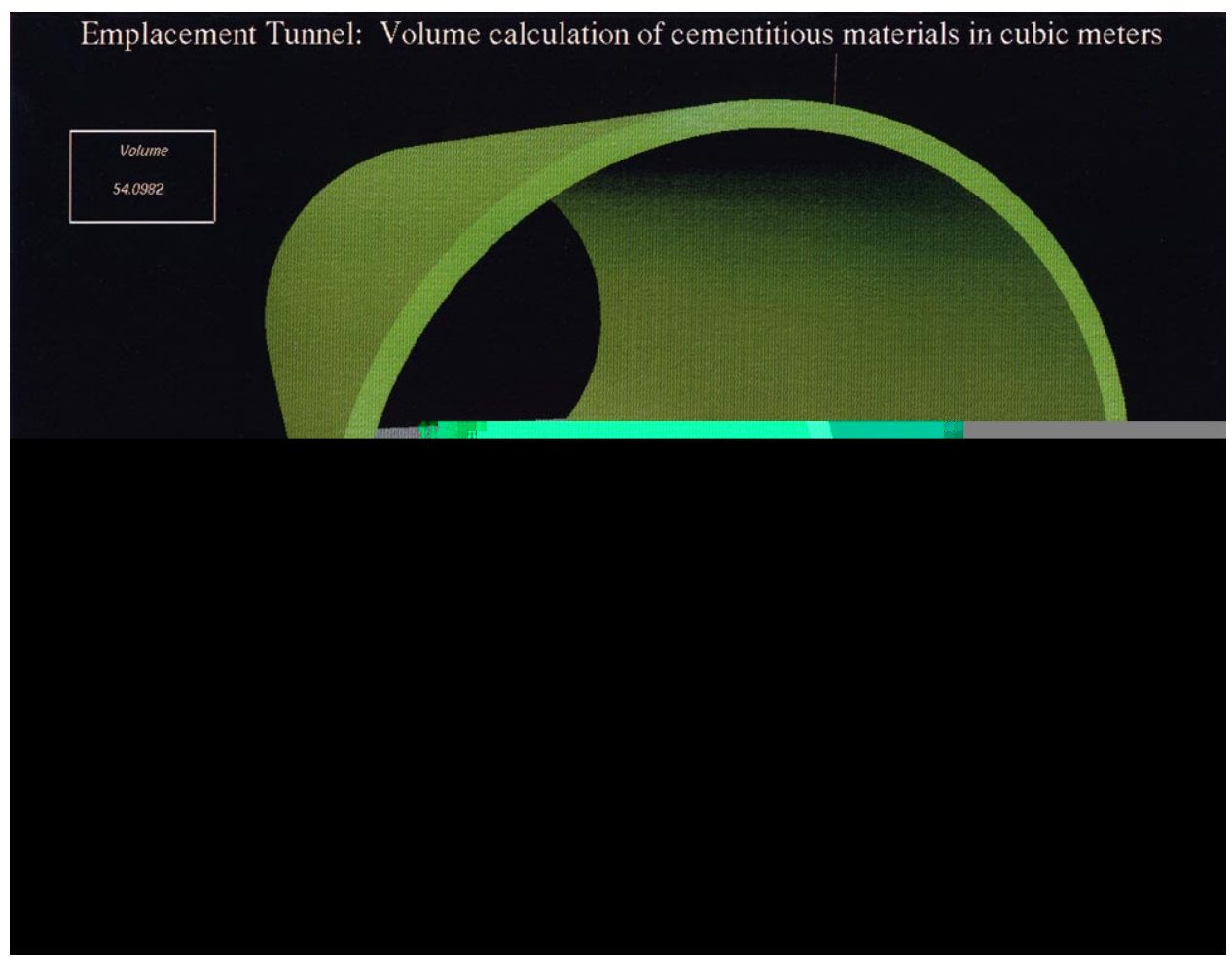

Figure 13. Volume of cementitious materials calculated for a 20 $\mathrm{m}$ section of a $4.3-\mathrm{m}-$ diam emplacement drift (about $54.1 \mathrm{~m}^{3}$ ). As shown, calculating material volumes is a straightforward procedure.

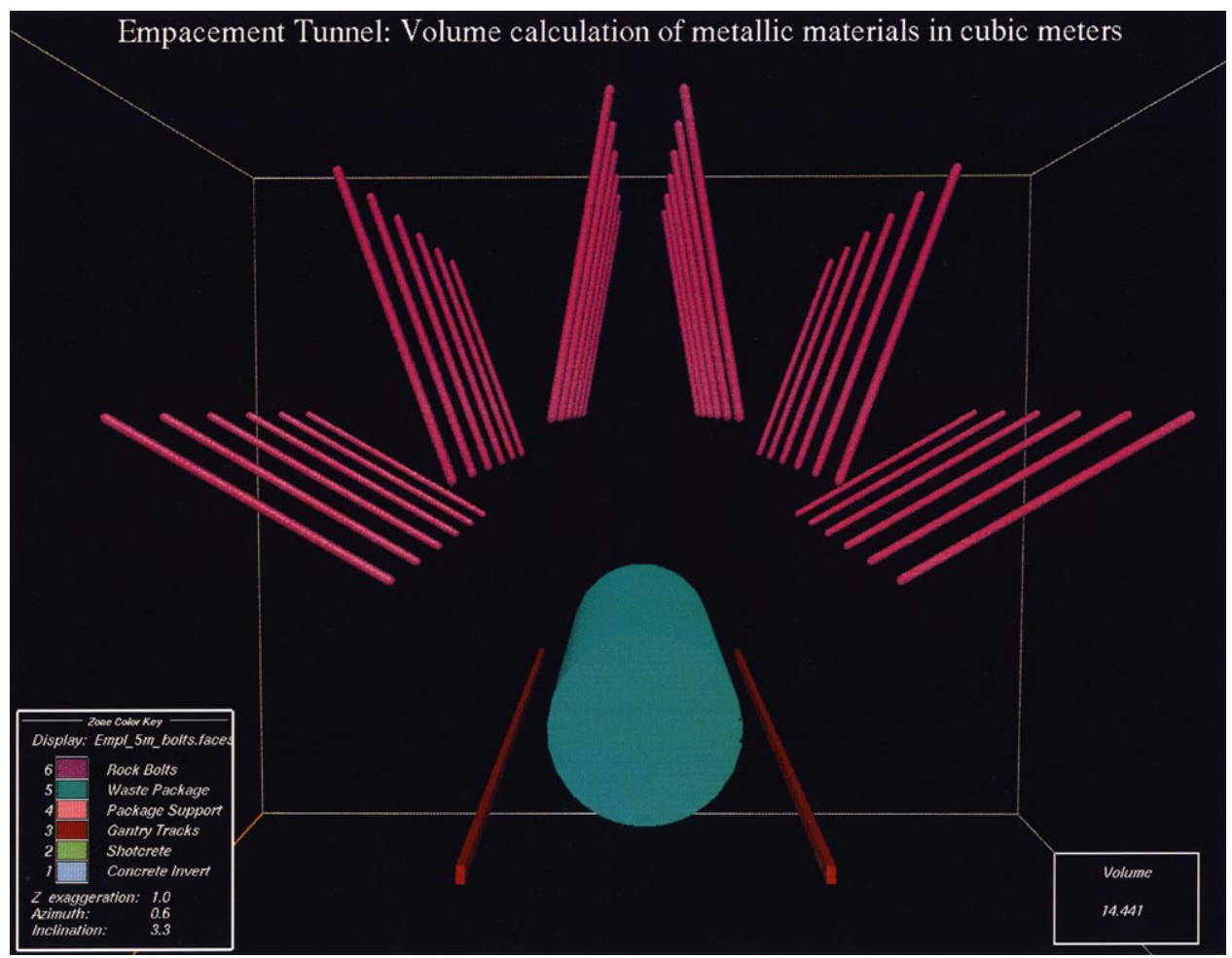

Figure 14. Volume of metallic materials calculated for a $20-\mathrm{m}$ section of a 4.3-mdiam emplacement drift. This volume is about $14.4 \mathrm{~m}^{3}$ including the waste packages, which have been modeled with a wall thickness of about $0.2 \mathrm{~m}$ (current design specifies a thickness of $0.12 \mathrm{~m}$ ). 


\section{The Module Concept: Developing the Capability to Model Complex Chemical Scenarios}

Modeling complex chemical scenarios in a natural environment over a long period of time will require the coupling of chemical processes that do not involve biological activity (abiotic) with those that do (biotic). In an unperturbed geological environment, the biotic processes may not be a significant factor in determining chemical reaction rates and the products of chemical reactions. However, in the perturbed setting of a radioactive waste repository, to which many potential microbial nutrients have been introduced, this potential exists.

Modeling natural chemical processes is most advanced in the area of abiotic models, which include inorganic chemistry as well as organic chemistry such as the nonbiological breakdown of petroleum products. In this area, the modeling codes and the extensive databases that are required to model complex abiotic processes, including the natural materials and many of the introduced materials (e.g., metals and petroleum products), are well developed and are based on first principles. There are specific materials, the most significant of which may be ordinary portland cement (OPC) compounds (depending on the finalized design concept and its requirements) for which the thermodynamic database could be improved. These issues are discussed in Section 3.2. In the case of organics, the kinetic parameters of the abiotic model require some adjustments to fit experimental data. However, adjustment of the abiotic model to reflect the abiotic degradation of organic materials may not be necessary because, as will be addressed in Section 3.3, the rate-determining factors may be microbial activity.

Microbially mediated chemical activity involves enzymes, which lower the activation energy of a chemical reaction and may result in the production of different chemical intermediates (Lehninger et al., 1993). Thus in the near-field environment, rates of reaction (including corrosion) as well as the chemistry of water in contact with waste packages and the composition and quantity of colloidal materials exiting the near-field environment may be significantly different than those predicted by abiotic models alone. To validate chemical predictions based on abiotic models, it must be established for each material and for applicable time periods that biotic activity is either insignificant or that the abiotic models are properly coupled with consistent biotic models. The coupling of abiotic and biotic models is not straightforward because abiotic models are rudimentary at best and, for the purpose of long-term modeling, are nonexistent.

To take advantage of existing modeling capabilities and to ameliorate codes of varying complexity, we plan to use a modular modeling environment. Preliminary steps to create this modeling environment have been conducted using Explorer ${ }^{\mathrm{TM}}$ software. The utility of this approach is explained Section 3.1.

\subsection{The Explorer TM Modular Modeling Environment}

Explorer ${ }^{\mathrm{TM}}$ software is most often used to visualize complex data sets from existing Fortran and $C$ programs, especially those for which properties are linked to a three-dimensional spatial coordinate system. However, because it has the capacity to accept user-built modules, it can also be used to encapsulate an existing program (in Fortran or in C) into a module (Figure 15). When used to develop complex chemical modeling capabilities, the modules-to which data can be introduced, variables modified, and other modules connected through a user interface-are interesting entities in themselves. For this purpose, multiple modules can be connected together, the connections establishing and documenting the flow of data (Figure 16). Thus, Explorer can provide an interface between any software output (e.g., Earth Vision and EQ3/6 or coupled geochemical hydrological codes).

As part of our work for the Introduced Materials Task, we are using Explorer ${ }^{\mathrm{TM}}$ to encapsulate the EQ3/6 software package, written in Fortran, into three modules: EQPT, EQ3NR, and EQ6. Once these three pieces are encapsulated into a module, they can be interconnected to form the EQ3/6 map (shown in Figure 16). The new system has the advantages of a visual system: direct visualization of simulation parameters in multiple dimensions, and 


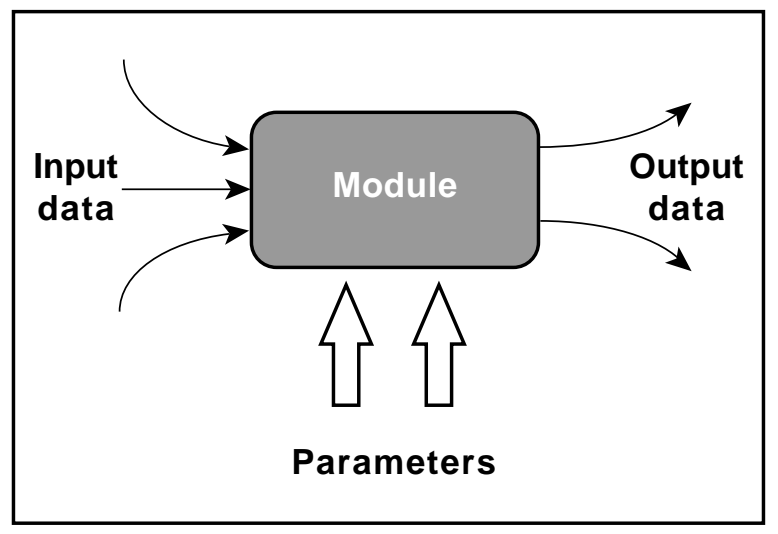

Figure 15. A single Explorer ${ }^{\mathrm{TM}}$ module functions independently.

the ability to control variables via easily monitored and manipulated widgets. This system will also enhance our ability to address computational complexity. The maps, which reproduce complex chemical modeling paths, can be archived. As such, they represent a step forward in the repetition of complex modeling scenarios and the documentation of computer modeling.

The ability to produce module maps and to imbed whole maps inside modules creates a functional hierarchy of computational maps. Thus, this ability provides a method for conducting the series of complex and repetitive calculations that must be used to develop chemical modeling capabilities and the simulation scenarios. First, and most immediately, this encapsulation facilitates database development. Second, it will help us develop materialspecific maps, which can be used to address and support design decisions. The first such map developed will be specific to cementitious materials. Third, encapsulation will allow us to introduce modules that can be used in concert with EQ3/6. These additional modules will address the chemical consequences of microbial activity that are not easily described by EQ3/6 (see Section 3.3).

\subsection{Abiotic Modules}

\subsubsection{The EQ3NR/EQ6 Modeling Code and Associated Databases}

The EQ3NR/EQ6 software package (Wolery 1992a,b; Wolery and Daveler, 1992) is composed of three executable programs (EQPT, EQ3NR, and EQ6)

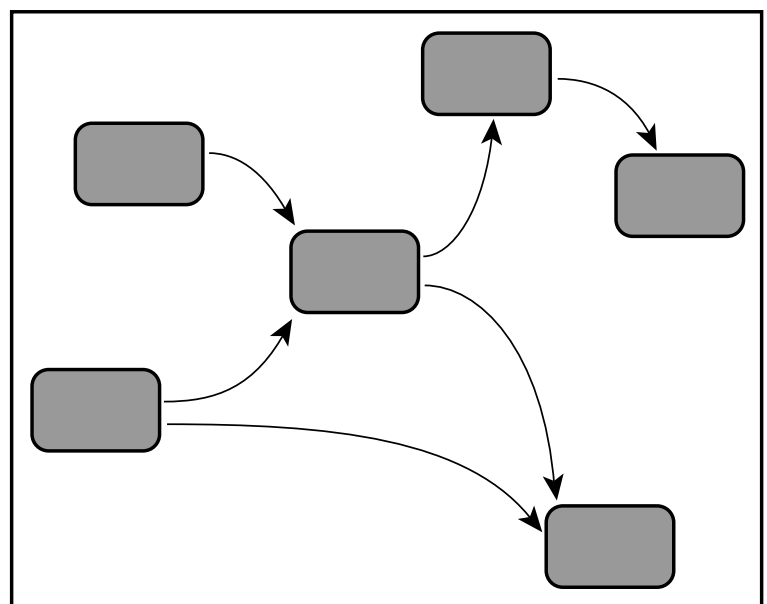

Figure 16. An Explorer ${ }^{\mathrm{TM}}$ map is a constellation of interconnected modules.

and a number of databases that are used at the modeler's discretion (Figure 17). Because EQPT simply formats databases to be readable by EQ3NR and EQ6, it is not shown in Figure 17. The input file for EQ3NR contains the analytical composition of the solution (including total concentrations of dissolved components, $\mathrm{pH}$, Eh, and oxygen fugacity). The code calculates the distribution of chemical species, using thermodynamic data located in the selected database. The output consists of an output and a pickup file, which is used to initialize the EQ6 input file.

EQ6 models the reaction of the aqueous solution with a set of minerals and gases, as well as fluid mixing and temperature changes. Five data files are now available. Three of these (COM, SUP, and NEA) may be used with either the Davies equation or the B-dot equation to calculate the activity coefficients. Their use is restricted to rather dilute solutions (ionic strength less than the seawater reference value). The two other data files (HMW and PIT) use Pitzer's (1979) equations and are suitable for modeling high-concentration solutions. Table 1 lists the salient features of each database, which are described as follows:

SUP database. Based entirely on the SUPCRT92 program (Johnson et al., 1992), the SUP database has a high level of internal consistency. The database covers a wide range of chemical species but does not contain much data related to calcium-silicatehydrate species that might be formed in cements at temperatures between 60 and $300^{\circ} \mathrm{C}$.

NEA database. The NEA database was produced by the Data Bank of the Nuclear Energy Agency of the European Community (Grenthe et al., 1989) and is specifically tailored to conduct uranium studies. 


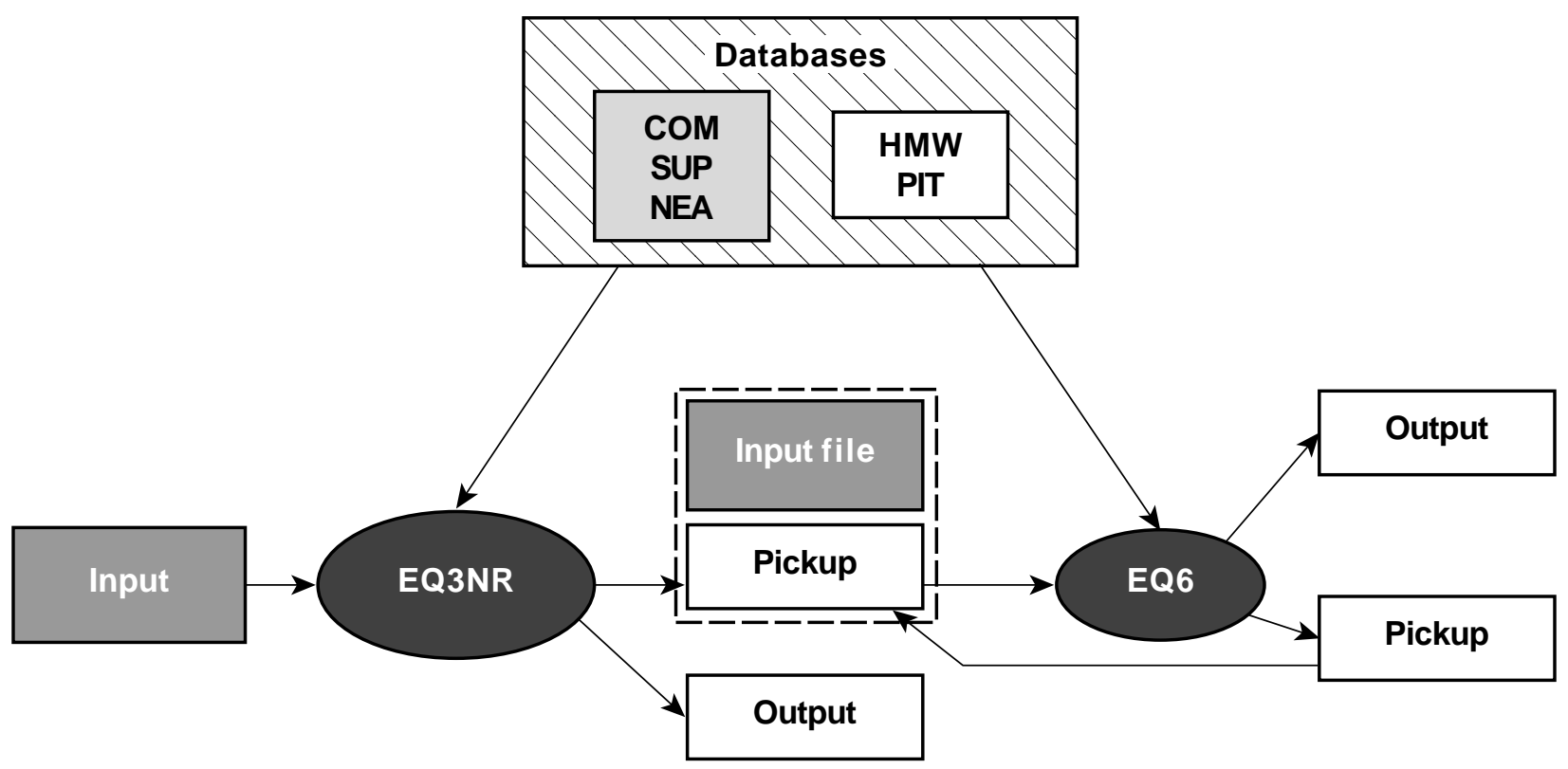

Figure 17. Schematic diagram of the flow of information between EQ3NR, EQ6, the databases, and the input and output files. Because EQPT simply formats databases to be readable by EQ3NR and EQ6, it is not shown in this figure.

Table 1: Databases available.

\begin{tabular}{llll}
\hline Database & Description & Formalism & Type of solutions \\
\hline SUP & SUPCRT92 & Debye-Hückel & Relatively dilute \\
NEA & & Davies, B-dot & Relatively dilute \\
HMW & Harvie et al. & Pitzer & $\begin{array}{l}\text { Dilute solutions to } \\
\text { concentrated brines }\end{array}$ \\
PIT & Pitzer & Pitzer & High concentrations \\
COM & Composite & Extended & Relatively dilute \\
\hline
\end{tabular}

HMW database. The HMW dataset is based on Harvie et al. (1984). It can be applied to both dilute solutions and concentrated brines at $25^{\circ} \mathrm{C}$. It also has a high degree of internal consistency, but it treats only the components present in the seawatersaltwater system. Important elements for modeling cement in a geologic repository, such as $\mathrm{Al}$ and $\mathrm{Si}$, are not included in this database.

PIT database. The PIT database is based primarily on data summarized by Pitzer (1979). This data file also can be applied to concentrated brines between 25 and $100^{\circ} \mathrm{C}$. It covers a larger set of species than the HMW database, but it does not address the silica and inorganic carbon species that are needed to model cement in a geologic repository. In addition, it contains some internal inconsistencies.

COM database. The COM dataset represents a melange of data found in the SUP and NEA datasets as well as data from the HMW dataset. Other data in this database were obtained by correlation or interpolation, so it offers the least assurance of internal consistency. However, it is the only means available for modeling problems with a high degree of compositional complexity. 


\subsubsection{Systems Containing Cementitious Materials}

Using the EQ3NR/EQ6 software package for geochemical modeling and the associated databases, we are also developing the capability to simulate the chemical behavior of cementitious systems. This work was originally conducted within the YMP International Program Fundamental Materials Task (USDOE/AECL Subagreement No. 2). The Fundamental Materials Task was completed in FY 1995, and the subsequent work is within the scope of the Introduced Materials Task. The ultimate goal is to create a module to simulate the abiotic degradation of cement using EQ3/6 and Explorer ${ }^{\mathrm{TM}}$ (Figure 18).

Within the Explorer ${ }^{\mathrm{TM}}$ framework, this module will operate independently or interact with other abiotic materials modules or modules that simulate the chemical effects of microbial activity. The part of the Fundamental Materials Task study described in this report is an assessment of the available thermodynamic databases. Each database has been developed with a specific need in mind. It has been fundamentally important, then, to demonstrate the capabilities of each database and to assess whether any of the databases is adequate and internally consistent for simulating chemical reactions related to cementitious materials in a geologic setting.

In this report, the terminology "cementitous material," refers to the suite of compounds that are formed using Portland cement (PC) grout. Usually aggregate or other additives are used to provide a formulation with desired curing properties, viscosity, and strength. Given that a number of formulations may be used in a potential repository for a variety of applications (e.g., invert, Fibercrete ${ }^{\mathrm{TM}}$ ), our initial effort has been to focus on the PC grout that is common to all the formulations.

PC grout is composed of about $67 \% \mathrm{CaO}$, $22 \% \mathrm{SiO}, 5 \% \mathrm{Al}_{2} \mathrm{O}_{3}, 5 \% \mathrm{Fe}_{2} \mathrm{O}_{3}$, and $3 \%$ other constituents (see, for example, Taylor, 1990). Given that the primary components of grouts are calcium and silicon oxides, the first step of this work was to define the requirements for including simulations of crystalline calcium-silicate-hydrate phases at elevated temperatures. These phases and their solid

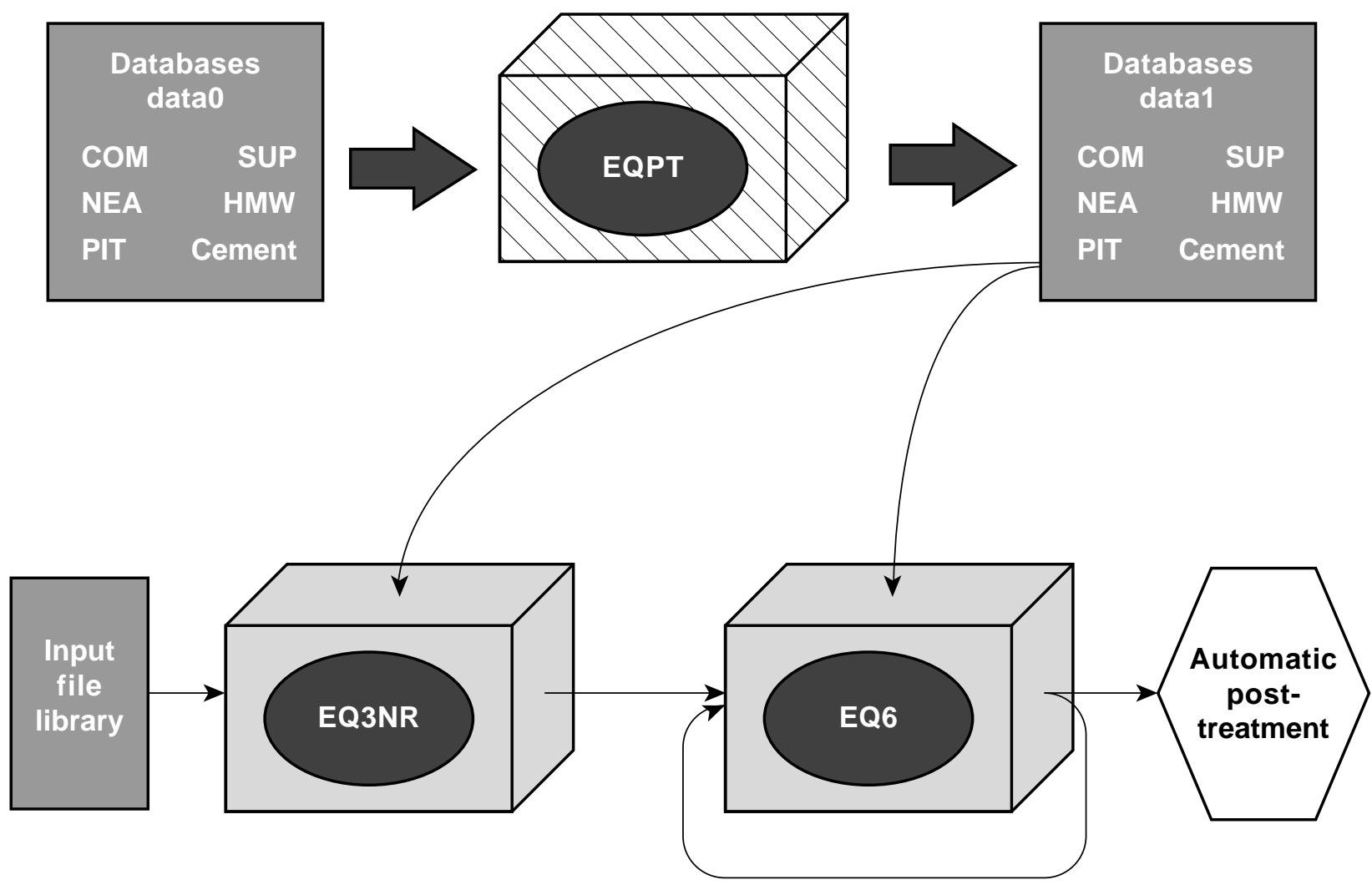

Figure 18. An illustration of the Explorer ${ }^{\mathrm{TM}}$ map concept applied to the EQ3/6 software package. Appropriate databases and defaults will streamline this module for simulating cement degradation. 
solutions are expected either to be present in cementitious materials or to be necessary to conduct chemical models of the phases that are present in cementitous materials. Carbon dioxide also has been included in this step because it reacts with many crystalline calcium-silicate-hydrate phases.

\subsubsection{Evaluating Common Minerals in the $\mathrm{Ca}-\mathrm{Si}-\mathrm{CO}_{2}-\mathrm{H}_{2} \mathrm{O}$ System}

In the first series of modeling exercises, we simulated the dissolution of calcite and wollastonite for temperatures between 25 and $90^{\circ} \mathrm{C}$. The relationship between the crystalline phases of the $\mathrm{Ca}-\mathrm{Si}-\mathrm{H}_{2} \mathrm{O}$ system and the prediction of chemical properties of cementitious materials at elevated temperature is discussed in Meike et al. (1994b) and Bruton et al. (1994). We have added a fourth component to the system to address the known sensitivity of some of the phases in the $\mathrm{Ca}-\mathrm{Si}-\mathrm{H}_{2} \mathrm{O}$ system to $\mathrm{CO}_{2}$. Detailed presentation and interpretation of the results are outside the scope of this document but will be described in the final report for the Fundamental Materials Task (YMP International Program, AECL/USDOE Subagreement No. 2) (to be published, depending on the program status). In this section, we present the type of work and the goal of the modeling work that is being conducted in this area.
At the time this work was conducted, the International Programs Fundamental Materials Task was the only area in the Yucca Mountain Project addressing issues related to the degradation of cementitious materials at elevated temperature. At present, the scope of that task has beenincorporated into the more general chemical modeling program of the Introduced Materials Task. Two extreme scenarios will ultimately be modeled and examined in full. One extreme represents the case in which the drifts experience free exchange with the atmosphere. In the chemical simulation, this scenario is represented by fixing the fugacities of the gases of interest, $\mathrm{O}_{2}$ and $\mathrm{CO}_{2}$ in the case of the current $\mathrm{Ca}-\mathrm{Si}-\mathrm{CO}_{2}-\mathrm{H}_{2} \mathrm{O}$ system. This is referred to as the "fixed" case. The other extreme represents the case in which the drifts are completely sealed from the atmosphere, and thus the gases are allowed to evolve through time. In the simulation, this scenario is represented by allowing the fugacities to evolve with reaction progress. This is referred to as the "unfixed" case. In both the fixed and unfixed cases, the gases are treated as separate reactants, analogous to a physical situation in which a gas reservoir is in contact with the fluid (Figure 19). The modeler chooses a value for the size of the reservoir; thus, another method of modeling an unventilated case is to fix the gas fugacities, but

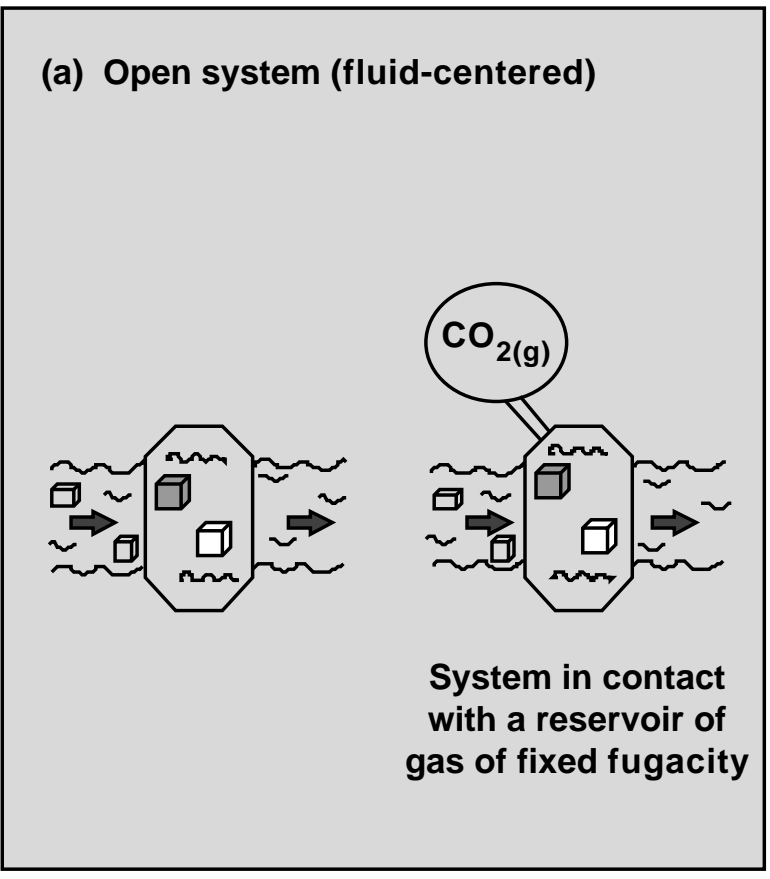

(b) Closed system
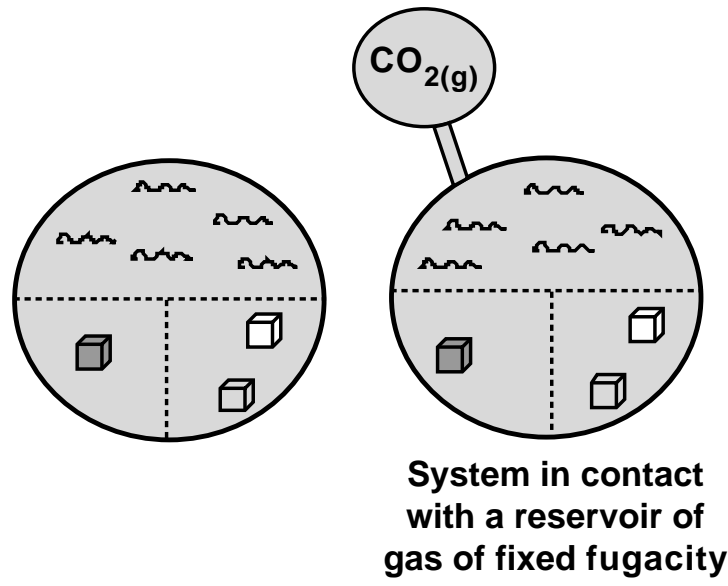

Figure 19. Schematic of (a) an open (fluid-centered) system and (b) a closed system for EQ3/6. 
choose a small reservoir size, which is depleted through the simulation. Conversely, to establish that a fixed-gas simulation represents a ventilated drift, the modeler must establish a large enough reservoir size that the fugacity at the end of the run is identical to the beginning.

Two other modeling options are possible that represent the physical nature of the system. These are referred to as "open" and "closed." The open system represents a packet of fluid that moves past mineral phases. In the simulation, this physical situation is modeled by excluding further reaction between the fluid and precipitated phases. The closed system simulation is analogous to a closed reservoir in which precipitated phases may continue to react with the fluid as it evolves. Open and closed systems will be investigated for both the fixed and unfixed cases. At this stage of the investigation, we have only pursued the fixed-gas scenario.

For each scenario, we simulated the evolution of five water compositions (Figure 20). These water compositions are the test cases available with the EQ3NR/EQ6 software package, and they cover a wide range of $\mathrm{pH}$ and salinity conditions. To date, we have studied three water compositions:

- J13 well water, which is commonly used to represent the groundwater composition in the Nevada Test Site.

- A seawater file that contains the full benchmark test case of Nordstrom et al. (1979).
- An acid mine water, which corresponds to an analysis of Nordstrom et al. (1979, their Table II, Column B) in the Hornet effluent.

We also are studying two other compositions:

- A carbonate aquifer groundwater composition that was part of Example 5 of INTERA (1983), a study comparing EQ3/ 6 with PHREEQE (Parkhust et al., 1980).

- A dead-sea brine composition, after Marcus (1977).

Only the COM and SUP data files could be tested for these simulations. The other databases were eliminated because elements important to this simulation were not represented. The NEA file contains data that are mainly relative to uranium. The PIT database is lacking data on silicon and carbon. Silicon is also lacking in the HMW database, and later, the lack of $\mathrm{Al}$ species will be of concern.

We conducted simulations at 25,50 , and $90^{\circ} \mathrm{C}$. The last two temperatures were selected in anticipation of future modeling comparisons between results obtained with these databases and results we will obtain with the thermodynamic data generated by Atkins et al. (1992, 1994). Figures 21 and 22 and Table 2 show the results obtained using the COM data file for the acid mine water composition at selected temperatures and $\mathrm{CO}_{2(\mathrm{~g})}$ partial pressures. As might be expected, a relationship between $\mathrm{pH}$ and $\mathrm{CO}_{2(\mathrm{~g})}$ partial pressure is clear in the closed system simulation (Figure 21). Thus, one would
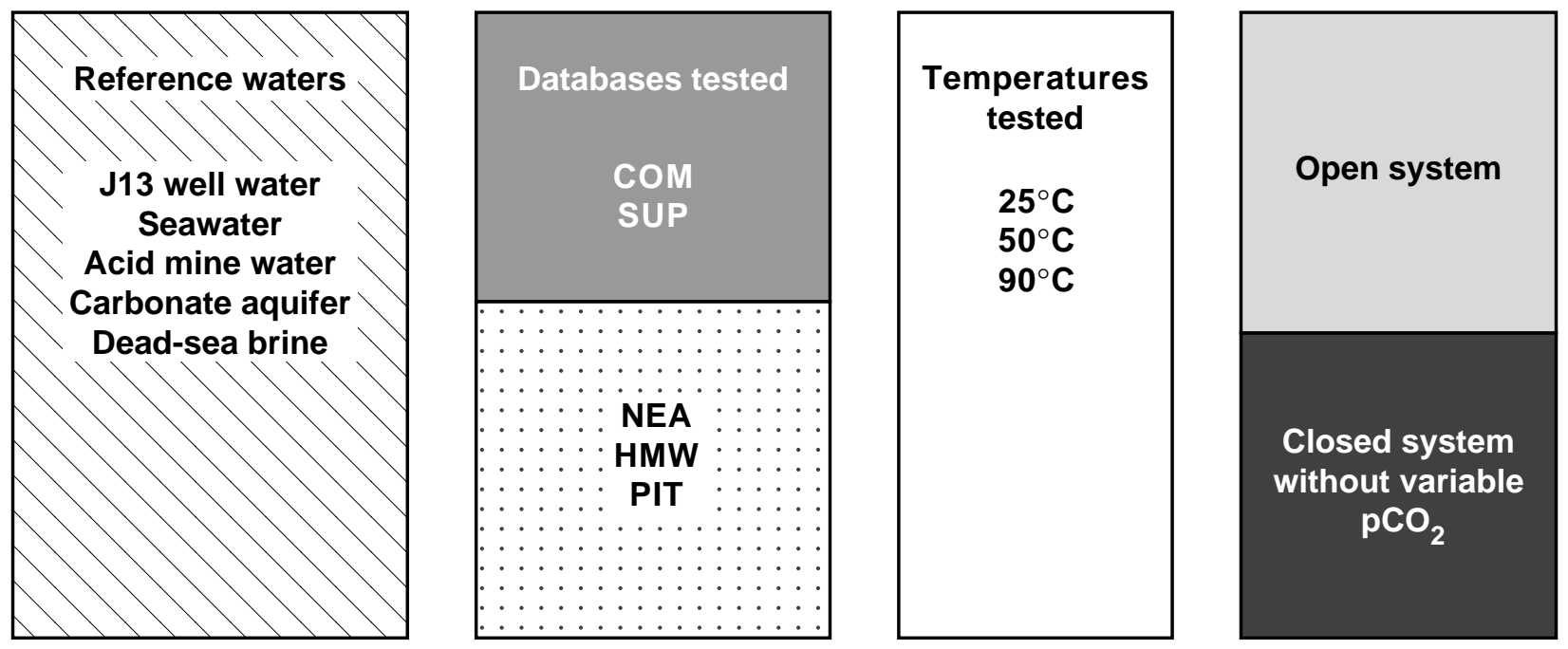

Figure 20. First series of modeling exercises. 


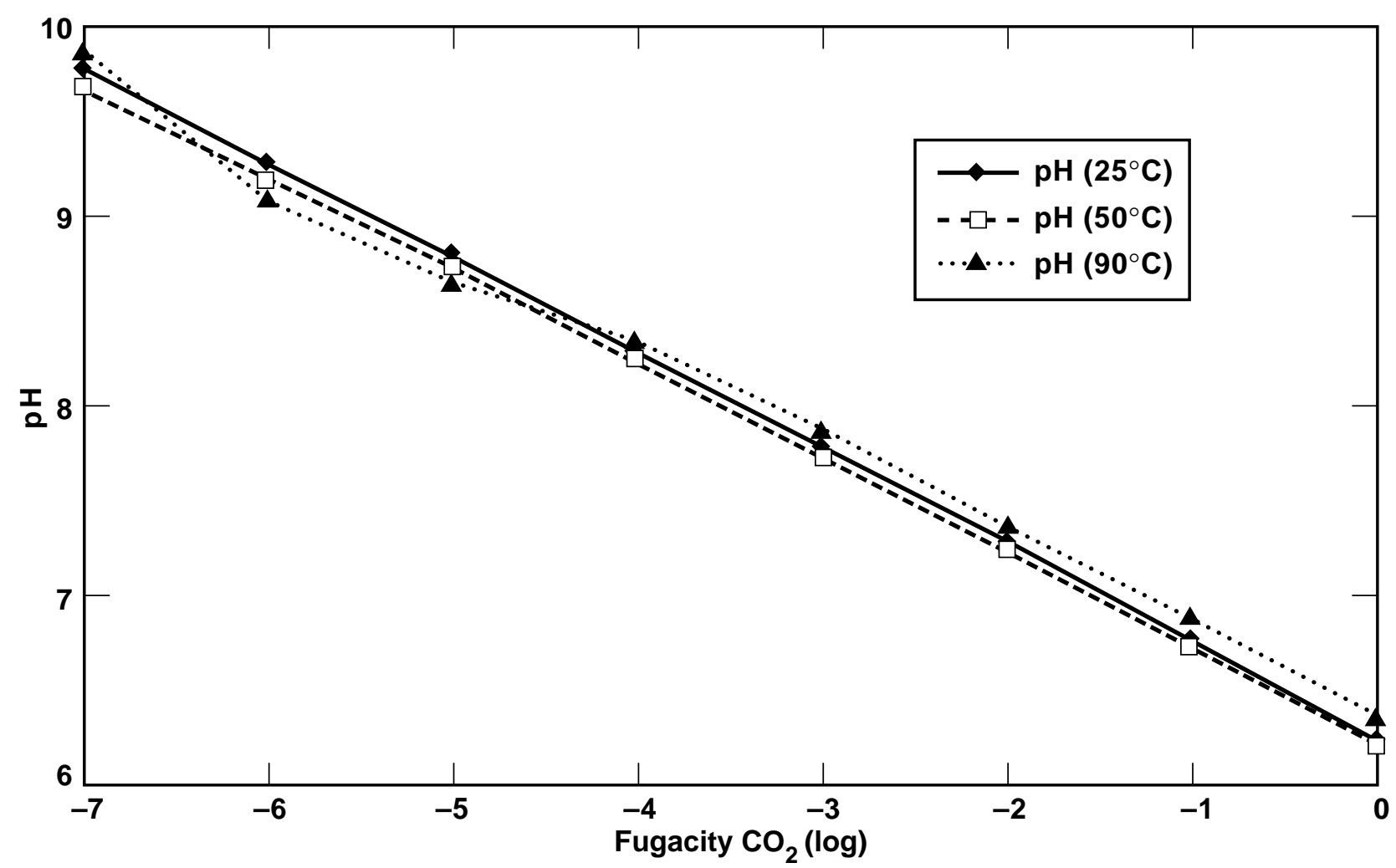

Figure 21. The linear relationship between $\mathrm{pH}$ and fugacity of $\mathrm{CO}_{2}$ (gas) in a closed system is clear in this simulation of the acid mine water in closed system mode at different temperatures.

Table 2: Acid mine water in the presence of 1 mole of wollastonite and 1 mole of calcite in a closed system at various temperatures and $\mathrm{CO}_{2}$ fugacities (given in log units).

\begin{tabular}{|c|c|c|}
\hline System & $\mathrm{pH}$ & Minerals \\
\hline $\begin{array}{l}\text { Open, } 25^{\circ} \mathrm{C} \\
\log f \mathrm{CO}_{2}=-3.4 \\
\left(2 \text { moles } \mathrm{CO}_{2} / \mathrm{kg} \mathrm{H}_{2} \mathrm{O}\right.\end{array}$ & 7.99 & $\begin{array}{l}\text { Alunite, ordered dolomite, gibbsite, } \\
\text { gypsum, hematite, jarosite, kaolinite, } \\
\text { nontronite- } \mathrm{H} \text {, quartz, stilbite, talc, } \\
\text { calcite, saponite, smectite }\end{array}$ \\
\hline $\begin{array}{l}\text { Closed, } 25^{\circ} \mathrm{C} \\
\log f \mathrm{CO}_{2}=-3.4\end{array}$ & 7.99 & $\begin{array}{l}\text { Gypsum, quartz, stilbite, calcite, } \\
\text { smectite }\end{array}$ \\
\hline $\begin{array}{l}\text { Closed, } 25^{\circ} \mathrm{C} \\
\log f \mathrm{CO}_{2}=-3.4\end{array}$ & 6.25 & $\begin{array}{l}\text { Gypsum, kaolinite, quartz, calcite, } \\
\text { smectite }\end{array}$ \\
\hline $\begin{array}{l}\text { Closed, } 50^{\circ} \mathrm{C} \\
\log f \mathrm{CO}_{2}=-3.4\end{array}$ & 6.21 & $\begin{array}{l}\text { Anhydrite, kaolinite, muscovite, } \\
\text { quartz, calcite, smectite }\end{array}$ \\
\hline
\end{tabular}




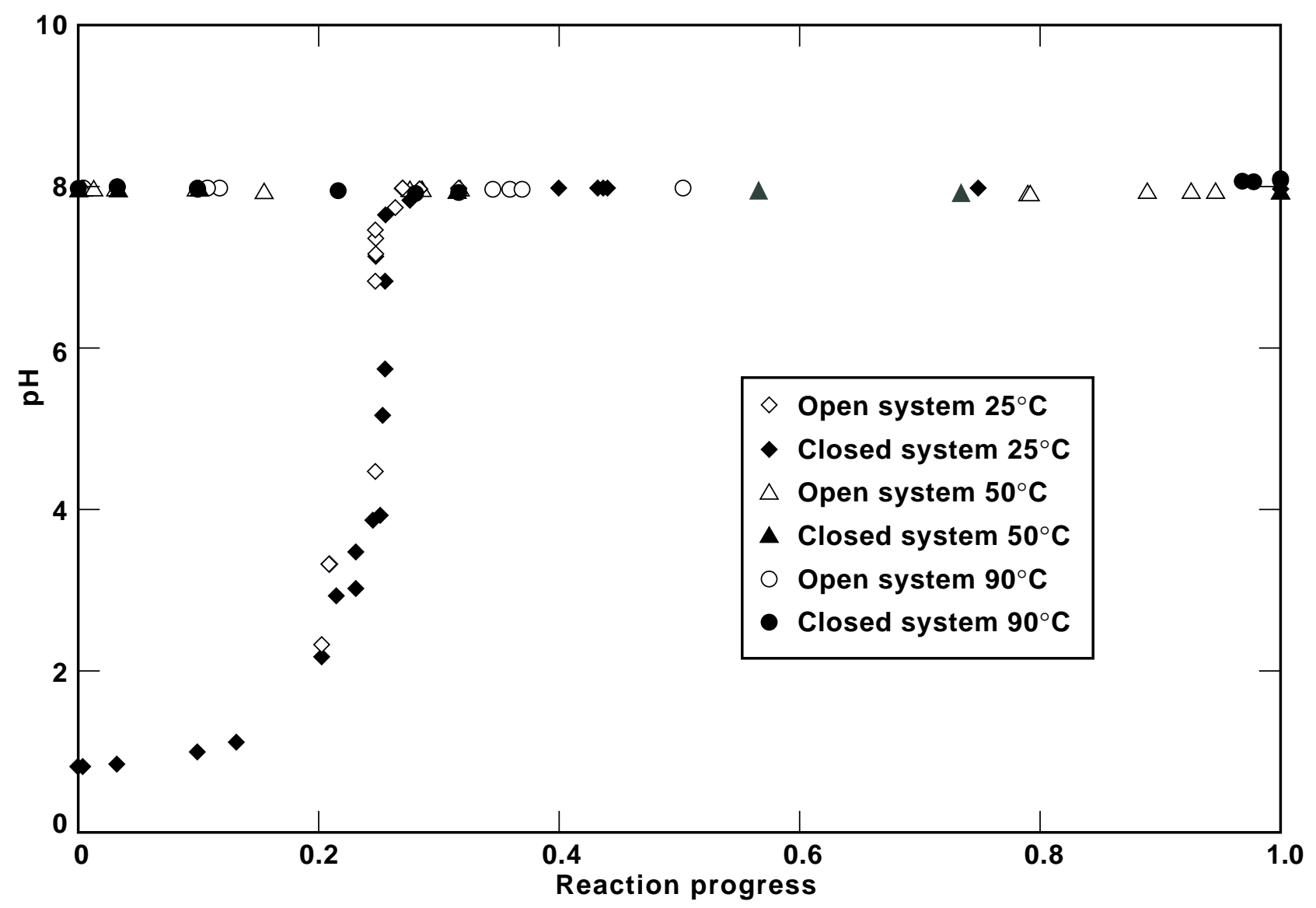

Figure 22. Evolution of $\mathrm{pH}$ as a function of reaction progress for the acid mine water in closed and open system modes at different temperatures.

expect the $\mathrm{pH}$ of the closed and open systems to evolve differently with reaction progress. However, in comparing the $\mathrm{pH}$ of open and closed systems as a function of reaction progress (Figure 22), we found that, within the chemical system and over the reaction time considered, temperature affects the evolution of $\mathrm{pH}$ more than the presence of a closed or open system does. The number of minerals obtained with the SUP data file (Table 2) is less important because of the smaller size of this file.

\subsubsection{Chemical Modeling of Available Crystalline $\mathrm{Ca}-\mathrm{Si}$-Hydrate Phases in the COM Database}

The second series of exercises concerns the thermodynamic data available for crystalline $\mathrm{Ca}-$ $\mathrm{Si}-$ hydrate phases in the COM data file. Simple modeling tests were conducted using 1 mole of each Ca-Si-hydrate phase (tobermorite- $11 \AA$ $(1.1 \mathrm{~nm})$, xonotlite, and okenite) in a liter of deionized water at $25^{\circ} \mathrm{C}$ with various partial pressures of $\mathrm{CO}_{2(\mathrm{~g})}\left(10^{-3.4}\right.$ to $\left.1 \mathrm{~atm}\right)$. For all of the partial pressures, the results show a complete dissolution of the $\mathrm{C}-\mathrm{S}-\mathrm{H}$ phase associated with the formation of quartz and calcite. The formation of quartz is not expected in this case; amorphous silica or cristobalite are the more likely $\mathrm{SiO}_{2}$ phases to form under these conditions. The set of thermodynamic data we used was put together to study natural rockground water interaction and does not contain some of the thermodynamic information necessary for modeling the cementitious systems in a natural environment (e.g., Bruton et al., 1994; Meike et al., 1994b). Thus, new thermodynamic data are being acquired, and geologic and extant databases for cement systems are being compiled to incorporate these new data. 


\subsubsection{Developing New Databases that Contain $\mathrm{Ca}-\mathrm{Si}-\mathrm{Hydrate}$ Phases}

Three data sets for the $\mathrm{Ca}-\mathrm{Al}-\mathrm{Si}-\mathrm{S}-\mathrm{Mg}-\mathrm{H}_{2} \mathrm{O}$ system were assembled by Atkins et al. $(1992,1994)$ for temperatures of 25,50 , and $90^{\circ} \mathrm{C}$. These data describe almost completely the composition of minerals in a cement system. A database file compatible with the EQ3/6 software package will be developed from these data using the GEMBOCHS software. A second CEMENT database is being developed in parallel through GEMBOCHS, using the SUP database as a starting point. These databases will be completed and tested against experimental data obtained within the Introduced Materials Task and data from the literature.

\subsection{Assessing the Needs for a Biotic Chemical Model}

There are numerous reasons for understanding the consequences of microbial activity on a highlevel radioactive waste repository and developing tools to predict them. Some of these are described in Horn and Meike (1995). Perhaps the most important reasons are to:

- Predict chemistry (both aqueous and material degradation, such as corrosion) and transport characteristics for long time periods in a setting that will contain natural and introduced microbes and in a manner that is consistent with existing abiotic chemical and hydrological models.

- Evaluate the effects of microbial activity on repository material behavior (e.g., corrosion and other types of degradation), and use the results to optimize repository design.

- Focus experimental work toward resolving the significant issues involved in the geologic storage of high-level radioactive waste.

As discussed in Horn and Meike (1995), microbes can significantly affect repository performance. They can affect the rates and mechanisms of metal corrosion, which is important in estimating the failure rate of waste containers. They can modify the chemistry of the groundwater in contact with repository materials, such as cement, including changes to the $\mathrm{pH}$ and Eh of the fluid (see, for example, Rogers, 1995) and may generate significant pressures of such gases as $\mathrm{CO}_{2}$ and $\mathrm{H}_{2} \mathrm{~S}$ as products of metabolic processes. These changes affect the degradation rates and mechanisms of all materials present in the repository (e.g., Rosevear, 1991). Finally, microbes also can produce organic compounds such as chelating ligands that can solubilize radionuclides once they escape a failed waste package.

Traditionally, microbiological studies tend to emphasize experimental studies or the study of natural systems. However, as in the abiotic case, modeling is the only way to rigorously examine the long-term effects of complex chemical systems that contain microbial populations. In addition, as various potential repository design options are considered (e.g., thermal loading, engineered barrier and waste package materials, and hydrologic regime), we need a convenient but robust method to make design choices based on an understanding of microbial activity, so we can minimize any potential negative effects that are determined to be significant. Clearly, a model that couples the relevant repository parameters with microbial effects and interfaces with relevant abiotic chemical and hydrological models is the best way to accomplish this task.

Microbially mediated chemistry that significantly modifies the abiotic chemical system must be included in the model to predict the chemical evolution of a high-level radioactive waste repository over long time periods. Such modeling can be approached from anywhere on a spectrum between two end extremes: (1) a mechanistic model that explicitly accounts for individual microbial metabolic processes, which are in turn coupled to all abiotic processes; and (2) a simple box model that treats microbial effects as simple chemical inputs or outputs from the system. It is desirable to generate a mechanistically based model that can more rigorously predict the effects of changing parameters on repository behavior, and that would be more compatible with the level of sophistication of the abiotic chemical modeling codes that have been applied to this project. However, the complexity and lack of quantification of most microbially influenced processes make such an approach unproductive at this time. The fact that microbes actively evolve, and different populations thrive as conditions change accentuate this difficulty (Hanselmann, 1986). Our intention then is to begin with the simple models described in Section 3.3.1. As we improve our 
understanding of the kinds of information required to construct the more sophisticated models described in Section 3.2.2, we will begin to develop models that can be integrated with existing abiotic aqueous chemical modeling codes, such as EQ3/6.

\subsubsection{Simple Models}

Although it is not possible to produce rigorous models of microbially related chemistry at this time, much progress may be made toward determining the relative significance of microbial effects with a simple box model.

A box model treats microbial processes as a simplified chemical reactor. We can view microbial reactions as enzymatically controlled chemical processes that are governed by the size, identity, and metabolic state of the microbial community as well as the traditional abiotic chemical parameters such as $\mathrm{pH}$ and temperature. Each microbe must have an energy supply, a source of carbon, and a set of nutrients essential for life. The energy supply generally involves an electron acceptor-donor process; the carbon supply is usually some form of organic matter or carbon dioxide; and most microbes need sufficient amounts of nitrogen, phosphorous, and sulfur to live. Other elements are needed in trace amounts but are generally not limiting in terms of microbial growth, especially in a heterogeneous repository environment. Water is also essential, and temperature is an important limiting factor. For a review of these considerations with regard to a potential repository at Yucca Mountain, see Horn and Meike (1995). Although specific microbes exist over subsets of this range, it is possible to establish, for this first step, a range of temperature over which microbes are active, as opposed to inactive (e.g., spore, dormant, or dead state).

The first step in using a box model to understand microbial effects in a repository is to establish limits to the total amount of microbial activity possible in the repository based on the microbial needs listed above (e.g., energy, carbon, nutrients, water, appropriate temperature). This type of approach is described well by McKinley and Hagenlocher (1993) for the Swiss High-Level Waste (HLW) and Low /Intermediate-Level Waste (LILW) repositories. They examine the energies available from all redox reactions possible for the materials present in the repository that can thus be used by microbes. This information is combined with an estimate of how much energy is needed to synthesize the compounds that make up biomass (this number is 0.1 mole of ATP ${ }^{1}$ to produce $1 \mathrm{~g}$ of dry cell mass, which is equivalent to $450 \mathrm{~kJ} /$ mole if the efficiency of energy utilization is $10 \%$ ). With this approach, the total biomass that can be sustained can be related to the masses of redox species that are present. Finally, if one can assume an average biomass metabolic rate, then the chemical effects of the biomass in terms of corrosion enhancement, ligand production, gas production, or any other rate of chemical change can be estimated and related to overall repository behavior.

A similar simplified approach can be used to determine the maximum possible biomass based on the amounts of essential nutrients (phosphorous, nitrogen, and sulfur) present in the repository. An average biomass is defined in McKinley and Hagenlocher (1993) to have the composition $\mathrm{C}_{160}\left(\mathrm{H}_{250} \mathrm{O}_{80}\right) \mathrm{N}_{30} \mathrm{P}_{2} \mathrm{~S}$. The total amount of possible biomass is simply the total amount of accessible nutrient divided by its weight fraction in biomass.

This calculation is complicated somewhat because nutrient availability may be a function of the corrosion rates of repository materials, whose rates themselves depend on active biomass. Some nutrients are available only if they are released during the corrosion of repository materials. The overall process is therefore coupled and amenable to modeling provided that some quantitative information on the type of coupling is available.

Applying this approach to the Swiss HLW repository, McKinley and Hagenlocher (1993) found that for a bounding calculation not limited by microbe mobility, the overall biomass was limited by energy availability - not nutrient availability. In particular, the amounts of nitrogen, phosphorous, and sulfur available in the backfill are much higher than the total mass of electron donors needed to fuel microbial growth. The only exception is during the first 10 years of repository existence where the availability of oxygen is expected to be high, and as a consequence, energy availability should also be high. The availability of $\mathrm{O}_{2}$ over time in a potential Yucca Mountain repository drift is still under discussion because boundary conditions have not been

\footnotetext{
${ }^{1}$ ATP carries chemical energy between metabolic pathways (see e.g., Lehninger et al., 1993).
} 
established for the availability of air through the mountain's fracture system, the amount of time that the repository drifts will be ventilated artificially, and the amount of chemically conditioned backfill that may affect the $\mathrm{fO}_{2}$. Although not necessarily completely analogous to the potential Yucca Mountain repository, it is illustrative to follow through the calculation as an exercise.

The biomass production rates calculated for the Swiss HLW repository range decrease from an initial rate of about $300 \mathrm{~g}$ of dry biomass/year for each waste package to long-term rates of about 0.3 $\mathrm{g} /$ year for each waste package. These values can be used to constrain likely production rates of byproducts such as organic ligands and gas generation, which in turn affect radionuclide transport rates and repository performance. For this case, even at maximum biological activity, the total production of organic complexing agents is only approximately equal to the estimated release rates of radionuclides. The net effect of microbial activity in terms of solubilization of radionuclides is therefore small for this repository.

Given that the conditions of the Swiss repository (e.g., granitic rock, repository design, saturated rock) are quite different, the findings of McKinley and Hagenlocher (1993) cannot be directly applied to a potential Yucca Mountain repository. However, this simple sort of analysis should be performed for a Yucca Mountain repository, to help prioritize work related to microbial activity. The approach could also be used to examine how repository performance affects changes to the material present in the repository, which would help us select the best materials for the engineered barrier design.

Information gained from this simple box model approach should be used to prioritize and guide more detailed work on microbial effects. More sophisticated models of microbial effects should then be generated using this more detailed information. However, because of the complex nature of microbial processes - in particular, their abilities to evolve with time and express new genes when environmental conditions change- and the diverse nature of microbial communities, it is unlikely that we could produce a reliable mechanistic chemical model for microbial behavior in the short term. Our best approach is to use our information on microbial behavior to define worst-case scenarios, identify parameters that limit microbial productivity, and incorporate these results into our task of designing the engineered barrier system.

\subsubsection{Using EQ3/6 to Model Microbial Effects}

Thermal and other perturbations of a microbially mediated chemical system occur as a complex function of microbial identity, microbial activity, and colony growth (biomass). In addition, individual species function over a relatively narrow temperature range. Thus, even with respect to the traditional chemical parameters, biological reactions operate according to different laws from those for abiotic reactions. However, although not identical to the abiotic case, it should be productive to take a similar approach to existing abiotic chemical modeling to use the chemical laws of microbial chemistry to predict long-term chemistry. This approach is also consistent with our ultimate goal, which is to develop models that can be operated in tandem with the abiotic models.

The net chemical effect of a community of microbes can be thought of as a set of mass inputs and outputs. For example, an autotrophic bacteria may take in bicarbonate as a carbon source, and it may oxidize iron to ferrous iron as an energy source. As by-products, the bacteria may make acetate and, as a consequence of oxidizing iron, lower the $\mathrm{pH}$. Using experimental observations of this type of bacteria in an environment similar to an anticipated repository environment, we should be able to write a reaction that describes the overall chemical effects of this bacterial population. For each gram of active biomass, we can relate a positive flux of acetate and acid generation, and a negative flux of iron and bicarbonate.

At the simplest level, models of microbial activity can be used as input into EQ3/ 6 (Wolery, 1992a). This approach offers the potential for modeling at a fairly high level of complexity in a short period of time. Although microbial activity is not explicitly provided for, the overall effect of microbial activity on repository corrosion processes can be. Such an approach allows us to account for the net effects of how microbes alter the local chemistry of their environments. Thus, the chemical effects of microbial activity can be rigorously coupled to material interactions in the repository without specific identification of all microbial 
species in the repository or explicitly providing for the details of microbial activity.

This type of model obviously lacks feedback from system parameters to the microbial processes. Feedback between environmental conditions and microbial activity is the most difficult part of implementing microbial activity into the simulation. However, if empirical relationships between microbial activity and environmental parameters such as temperature and $\mathrm{pH}$ are available, they can be readily incorporated into the simulation. For example, microbial productivity is almost certainly $\mathrm{pH}$ dependent. Most bacteria live only over a restricted $\mathrm{pH}$ range.

The next step in making this type of model more realistic would be to incorporate feedback between environmental parameters and microbial productivity. If the $\mathrm{pH}$ changed significantly, it is likely that a new type of microbial population would exist, with a different set of chemical effects. Likewise, if microbial activity were to change the $\mathrm{pH}$, the equilibrium condition between the aqueous fluid and the material with which it is in contact would be changed. EQ3/6 can incorporate these types of complexities into the simulation. Experimental data on the biomass production rates of any variety of microbial populations that are dependent on $\mathrm{pH}$, or on any other parameter related to the chemical response or influence of microbial activity, can be entered as reactants in the simulation. Kinetic control of these rates is also possible if appropriate rate data are known. Given the complexity and interdependency of some of these factors, it may be necessary to enter the numerical relationships as reactants into EQ3/6 and, in a stepwise or iterative fashion, to consider the chemical effects of the microbial population.

The presence of other repository materials can also be included in the simulation so that coupling between all chemical processes is properly accounted for. For example, the simulation may include the host rock, a metal canister, and cement. As the reaction proceeds, we must account for the effect of acid generation on $\mathrm{pH}$ stability, the effect of acetate generation on metal corrosion, and the effects of using bicarbonate. The system will evolve and have a $\mathrm{pH}$ that is controlled by the coupled interactions of all these $\mathrm{pH}$-dependent reactions. Likewise, the complete solution composition can be calculated for any step along this reaction process.
The ability to do this stage of modeling will be enhanced by the use of Explorer ${ }^{\mathrm{TM}}$ software.

Our ultimate aim is to find an approach that can be integrated into a sophisticated feedback link with the existing EQ3/ 6 code. We aim to frame descriptions of microbial activity in forms that mimic the abiotic thermodynamic and kinetic descriptions. To do this, we must distinguish between the two types of processes: (1) those that can be seen as perturbations from an equilibrium state, or as part of a new, microbially mediated equilibrium state, and thus comprise a module that will interact with EQ3; and (2) those that affect rates of change, and therefore the kinetics, and thus comprise a module that will interact with EQ6 (Figure 23).

In developing the descriptions, we seek to define microbial activities in terms of three types of processes: processes or conditions that can represent standard states, those that can be described in terms of rates of change, and those in which transfer of mass, energy, or other quantifiable units sum to zero. We will define standard states as points of reference so we can quantify deviations from those points. Describing processes in terms of equations that sum to zero has many advantages. For example, it ensures internal consistency and provides a foundation for expanding from simple to multicomponent systems.

\subsection{Electronic Structure Calculations of $\mathrm{Ca}-\mathrm{Si}-\mathrm{Hydrates}$}

Many phases in the crystalline $\mathrm{Ca}-\mathrm{Si}-\mathrm{H}_{2} \mathrm{O}$ system can develop in cement exposed for long time periods to temperatures above $25^{\circ} \mathrm{C}$. The phases themselves are found both naturally and in synthetic systems. As a consequence of their appearance in cements exposed to elevated temperatures, chemical reactions involving these phases can affect not only water chemistry (see Sections 3.1 and 3.2) but also the relative humidity of a radioactive waste repository that contains significant amounts of cement. To predict and simulate these chemical reactions, we are developing an internally consistent database of crystalline Ca-Si-hydrate structures (see Section 3.2). The experimental aspects of the synthesis and characterization of pure phases for the purpose of measuring thermodynamic parameters is discussed elsewhere (e.g., Barnes et al., 1996; Martin, 1995; Bruton et al., 1994; Meike et al., 1994b). However, 


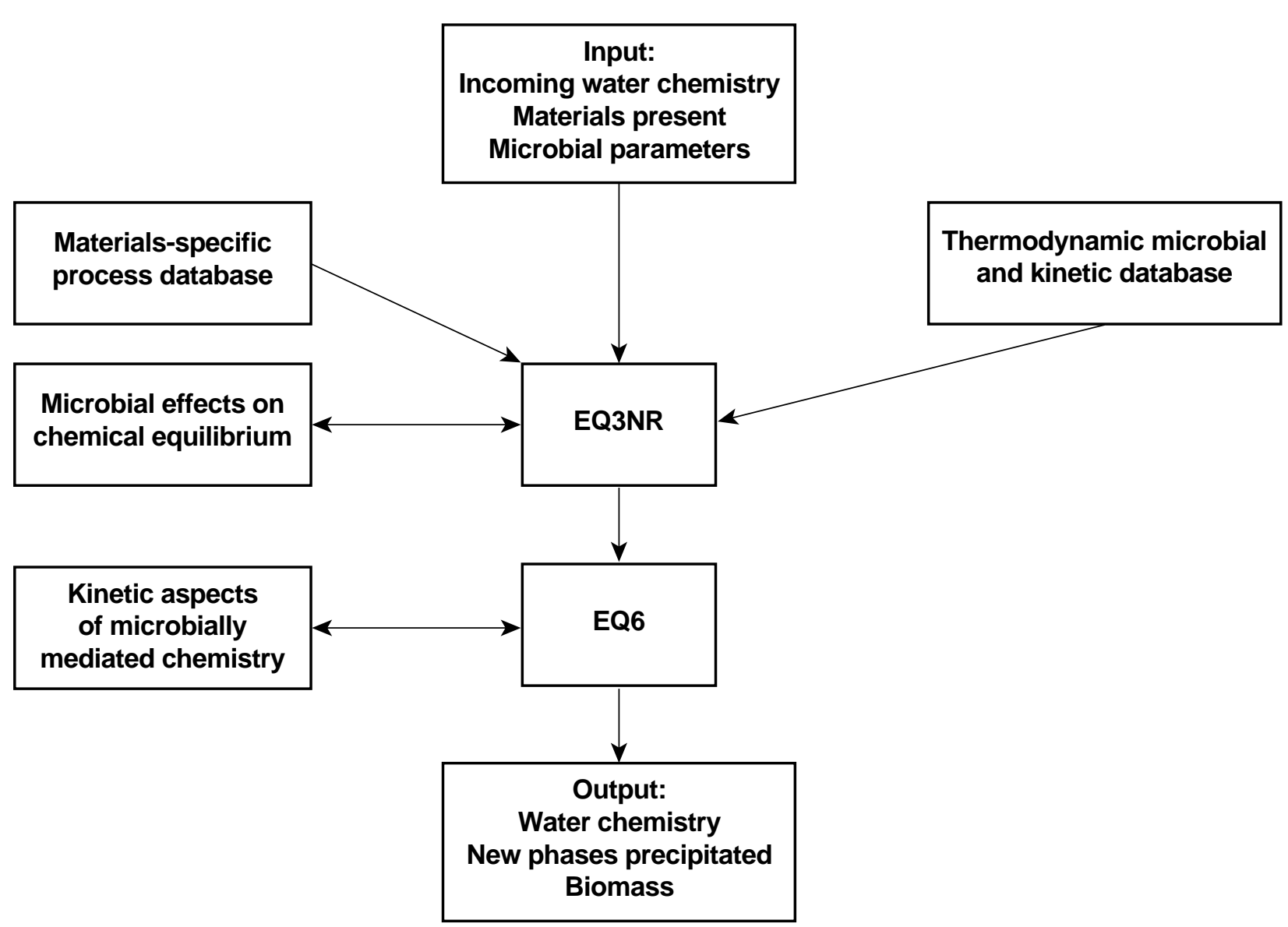

Figure 23. Diagram of the interlinks between an existing modularized code for abiotic aqueous chemical simulation and planned microbial modules.

given the difficulties inherent in directly measuring the thermodynamic parameters of these phases, we have undertaken a set of first-principles electronic structure calculations.

Electronic structure calculations, and the linear muffin-tin orbital theory in particular, are standard methods for approaching the physical properties of metals and metal alloys, semiconductors, and simple insulators (see, for example, Anderson, 1975; Skriver, 1984). In the past, these methods have been confined to small systems of less than 20 atoms in a unit cell. Thus, calculations for wollastonite and xonotlite, which contain a 30-atom unit cell and a 62-atom unit cell, respectively, would normally have been out of reach. However, recent developments in algorithms and computer power have brought larger systems within the range of these calculational techniques.

The goal of this modeling effort is to determine the energetics of hydration for crystalline $\mathrm{Ca}-\mathrm{Si}-$ hydrate phases. The work performed to date repre- sents an initial step in this direction. The initial results for the first phases undertaken represent the water-poor end members, wollastonite $\left(\mathrm{CaSiO}_{3}\right)$ and xonotlite $\left(\mathrm{Ca}_{6} \mathrm{Si}_{6} \mathrm{O}_{17}(\mathrm{OH})_{2}\right)$. The results, reported in Sterne and Meike (1995), are summarized here.

The calculated ground-state properties of wollastonite and xonotlite are in good agreement with experiment and provide equilibrium lattice parameters within 1 to $1.4 \%$ of the experimentally reported values. The roles of the different types of oxygen atoms, which are fundamental to understanding the energetics of crystalline $\mathrm{Ca}-\mathrm{Si}-$ hydrates, examined in terms of their electronic state densities, appear to be in good agreement with experiment for the lattice parameters and internally consistent when comparisons are drawn between the two structures. The exercise, completed with wollastonite and xonotlite, demonstrates the applicability of these electronic structure methods in calculating the fundamental properties of these phases. 
The electronic structure calculation methods are demonstrated to give reliable results, even for the relatively large wollastonite and xonotlite unit cells. Thus, applying this new approach to the study of calcium silicate hydrates appears to be fruitful not only in terms of the ability to calculate heats of formation but also by virtue of the insight that it can provide into the nature of hydration and dehydration. 


\section{Summary}

The modeling activities required to predict the chemistry of water in contact with concrete and its degradation products cover a broad area, from developing databases for existing abiotic codes, to developing codes that can simulate the chemical impact of microbial activities at a level of sophistication equivalent to that of the abiotic modeling codes, and ultimately, to simulating drift-scale chemical systems in support of hydrological, geochemical, and engineering efforts.

This report primarily describes the conceptual framework upon which work in all of these areas will be built. Although the present report is specific to the development of models to simulate the degradation of cementitious materials, similar effort is required for all types of construction materials that might be used in a potential repository. Developing such models will require a strong interaction between the integration, experimental, and modeling activities within the Introduced Materials Task as well as interactions with researchers working on repository and waste package design, performance assessment, and near-field environment technical areas. 


\section{References}

Anderson, O. K. (1975), Phys. Rev. B 12, 3060.

Atkins, M., D. Bennett, A. Dawes, F. P. Glasser, A. Kindness, and D. Read (1992), A Thermodynamic Model for Blended Cements, U.S. Department of Energy, Washington, DC, DOE/HMIP/RR/92/005.

Atkins, M., F. P. Glasser, L. P. Moroni, and J. J. Jack (1994), Thermodynamic Modelling of Blended Cements at Elevated Temperature $\left(50-90^{\circ} \mathrm{C}\right)$, U.S. Department of Energy, Washington, DC, DOE/HMIP/RR/94/011.

Barnes, D. E., J. Del Castillo, C. C. Hoellwarth, P. Klavins, and R. N. Shelton (1996), Development of Techniques for Heat Capacity Measurements of Crystalline Calcium Silicate Hydrate Phases, Final Report submitted on Completion of Research Contract/Grant No: LLNL-IUT B291486 to the Fundamental Materials Task at LLNL, OCRWM International Program.

Bruton, C. J., W. E. Glassley, and A. Meike (1995), Geothermal Areas as Analogues to Chemical Processes in the Near-Field and Altered Zone of the Potential Yucca Mountain, Nevada Repository, LLNL, Lawrence Livermore National Laboratory, Livermore, CA, UCRL-ID-119842. MOL.19960408.0210

Bruton, C. J., B. L. Phillips, A. Meike, S. Martin, and B. E. Viani (1994), “Cement Minerals at Elevated Temperature: Thermodynamics and Structural Characteristics," Proc. Mater. Res. Soc. Fall 1993, pp. 327-333.

Grenthe, I., R. J. Lemire, A. B. Muller, C. NguyenTrung, and H. Wanner (1989), NEA-TDB Chemical Thermodynamics of Uranium, OECD-Nuclear Energy Agency, Saclay, France (draft manuscript; NNA.900815.0013).

Hanselmann, K. W. (1986), “Microbially Mediated Processes in Environmental Chemistry," Chimia 40, 146-159.

Harvie, C. E., N. Moller, and J. H. Weare (1984), "The Prediction of Mineral Solubilities in Natural Waters: The $\mathrm{Na}-\mathrm{K}-\mathrm{Mg}-\mathrm{Ca}-\mathrm{H}-\mathrm{Cl}-\mathrm{SO}_{4}-$
$\mathrm{OH}-\mathrm{CO}_{3}-\mathrm{HCO}_{3}-\mathrm{CO}_{2}-\mathrm{H}_{2} \mathrm{O}$ System to High Ionic Concentrations at $25^{\circ} \mathrm{C}$," Geochim. Cosmochim. Acta 48, 981-997

Horn, J. M., and A. Meike (1995), Microbial Activity at Yucca Mountain, Part I: Microbial Metabolism, Adaptation and the Repository Environment, Position Paper resulting from the Workshop on Microbial Activity at Yucca Mountain, Lafayette, California, April 10-12, 1995, Lawrence Livermore National Laboratory, Livermore, CA, UCRL-ID-122256.

INTERA Environmental Consultants, Inc. (1983), Geochemical Models Suitable for Performance Assessment of Nuclear Waste Storage: Comparison of PHREEQE and EQ3/EQ6, Office of Nuclear Waste Isolation, Battelle Project Management Division, Columbus, OH, ONWI-473, 114 p.

Johnson J. W., E. H. Oelkers, and H. C. Hjelgeson (1992), "SUPCRT92: A Software Package for Calculating the Standard Molal Thermodynamic Properties of Minerals, Gases, Aqueous Species, and Reactions from 1 to 5000 bars and $0^{\circ} \mathrm{C}$ to $1000^{\circ} \mathrm{C}$," Computers Geosci. 18, 899-947.

Lehninger, A. L., D. L. Nelson, and M. M. Cox (1993), Principles of Biochemistry, Worth Publishers, New York, 1013 p.

McKinley, I. G., and I. Hagenlocher (1993), “Quantification of Microbial Activity in a Nuclear Waste Repository," in ISSM'93 (Bath, United Kingdom), pp. 1-24.

Marcus, Y. (1977), "The Activities of Potassium Chloride and of Water in Dead Sea Brine," Geochim. Cosmochim. Acta 41, 1739-1744.

Martin, S. I. (1995), "Synthesis of 1.1-nm Tobermorite: A Cement Phase Expected under Repository Conditions," presented at the International High-Level Radioactive Waste Conference (Las Vegas, NV).

Meike, A., and M. Spragge (1995), Progress Report\#1 on the Materials Identification, Characterization, and Evaluation Activity: Acquisition of Materials Data from the Exploratory Studies Facility, Yucca 
Mountain Site Characterization Project Introduced Materials Milestone: MOL 132.

Meike, A., W. L. Bourcier, M. Alai, D. L. Haldeman, P. S. Amy, and T. Lagadinos (1994a), Potential Long-Term Chemical Effects of Diesel Fuel Emissions on a Mining Environment: A Preliminary Assessment Based on Data from a Deep, Subsurface Tunnel at Rainier Mesa, Nevada Test Site, Lawrence Livermore National Laboratory, Livermore, CA, UCRL-ID-121046.

Meike, A., M. Onofrei, C. J. Bruton, and B. E. Viani (1994b), "Progress in Understanding the Structure and Thermodynamics of Calcium Silicate Hydrates," in High Level Radioactive Waste Management, Proc. Fifth Annual Int. Conf. (Las Vegas, NV, May 1994), pp. 2590-2596.

Nordstrom, D. K., E. A. Jenne, and J. W. Ball (1979), "Redox Equilibria of Iron in Acid Mine Waters," in Chemical Modeling in Aqueous Systems, E.A. Jenne, Ed. ACS Symposium Series, Vol. 93 (American Chemical Society, Washington, DC), pp. 51-79.

Nuclear Regulatory Commission (1988), Disposal of High-Level Radioactive Wastes in Geologic Repositories: Licensing Procedures, U.S. Nuclear Regulatory Commission, Washington, DC.

Nuclear Regulatory Commission (1990), Disposal of High-Level Radioactive Wastes in Geologic Repositories: Licensing Procedures, Code of Federal Regulations, Energy, Title 10, Part 60, Washington DC.

Nuclear Waste Policy Act of 1982 (1983), Public Law L97-425.

Parkhust, D. L., D. C. Thostenson, and L. N. Plummer (1980), PHREEQE, a Computer Program for Geochemical Calculations: Water Resources Investigation, U.S. Geological Survey, Reston, VA, Report 80-96, 210 p.

Pitzer, K. S. (1979), “Theory: Ion Interaction Approach," in Activity Coefficients in Electrolyte Solutions, R. M. Pytkowicz, Ed. (CRC Press, Boca Raton, FL), pp. 157-208.

Rogers, R. D. (1995), Assessment of the Effects of Microbially Influenced Degradation on a Massive
Concrete Structure. Final Report to the Introduced Materials Task, Biodegradation Systems, Inc., Lawrence Livermore National Laboratory, Livermore, CA, UCRL-CR-122068.

Rosevear, A. (1991), "Review of National Research Programmes on the Microbiology of Radioactive Waste Disposal," Harwell Laboratory, United Kingdom Atomic Energy Administration, Oxfordshire, United Kingdom, Report NSS/R263.

Sterne, P. A., and A. Meike (1995), "Electronic Structure Calculations of Calcium Silicate Hydrates," in Proc. Mater. Res. Soc. Meeting Symp. V (Boston, MA).

Skriver (1984), The LMTO Method, Vol. 42, Springer Series in Solid State Sciences (Springer, New York).

Taylor, H. F. W. (1990), Cement Chemistry (Academic Press, New York), $475 \mathrm{p}$.

West, K. A. (1988), Nevada Nuclear Waste Storage Investigations Exploratory Shaft Facility Fluids and Materials Evaluation, Los Alamos National Laboratory, Los Alamos, NM, LA-11398-MS; NN1.19981213.0021.

Wolery, T. J. (1992a), EQ3NR, A Computer Program for Geochemical Aqueous Speciation-Solubility Calculations: Theoretical Manual, User's Guide, and Related Documentation (Version 7.0), Lawrence Livermore National Laboratory, Livermore, CA, UCRL-MA-110662 PT III.

Wolery, T. J. (1992b), EQ3/6, A Software Package for Geochemical Modeling of Aqueous Systems: Package Overview and Installation Guide. 2.3 Outline of Modules and Relationships Showing the Integration between Existing Modules and Those that Require Development, Lawrence Livermore National Laboratory, Livermore, CA, UCRLMA-110662 PT I.

Wolery, T. J., and S. A. Daveler (1992), EQ6, A Computer Code for Reaction-Modeling of Aqueous Geochemical Systems: Theoretical Manual, User's Guide, and Related Documentation (Version 7.0), Lawrence Livermore National Laboratory, Livermore, CA, UCRL-MA-110662 PT IV. 


\section{Appendix A: Materials Used in the ESF North Ramp}

In this appendix, we describe the materials used to build the north ramp of the Exploratory Studies Facility (ESF). This information was provided to the Introduced Materials Task by Ralph Dow (personal communication to A. Meike, 1995).

\section{Shotcrete}

Reference: Wet Mix shotcrete.

Specification: BABEAB000-01717-6300-03363

Rev 01 Shotcrete Mix No. 501:

\begin{tabular}{|c|c|c|}
\hline Material & $\begin{array}{l}\text { ASTM } \\
\text { reference }\end{array}$ & Weight \\
\hline $\begin{array}{l}\text { Cement } \\
\text { (Type 11) }\end{array}$ & $\mathrm{Cl} 50$ & $775 \mathrm{lb} / \mathrm{yd}^{3}$ \\
\hline Aggregates & C33 & $\begin{array}{l}\text { CA } 126 \mathrm{l} / \\
\text { FA1539 lb/yd }\end{array}$ \\
\hline Water & C94 & $\begin{array}{l}352 \mathrm{lb} / \mathrm{yd}^{3} \\
(42.3 \mathrm{gal})\end{array}$ \\
\hline \multicolumn{3}{|c|}{ Admixtures } \\
\hline $\begin{array}{l}\text { Master } \\
\text { Builders } \\
\text { Polyheed } \\
\text { (WRA) }\end{array}$ & & $93 \mathrm{oz} / \mathrm{yd}^{3}$ \\
\hline $\begin{array}{l}\text { Master } \\
\text { Builders } \\
\text { QSL-100 } \\
\text { Shotcrete } \\
\text { Accelerator }\end{array}$ & $\begin{array}{c}\mathrm{Cl} 240 \\
\text { (silica fume) } \\
\text { C1141 } \\
\text { (except } \\
\text { silica fume) }\end{array}$ & $\sim 48-50 \mathrm{lb} / \mathrm{yd}^{3}$ \\
\hline \multicolumn{3}{|l|}{ Slump = 2 in. } \\
\hline $\mathrm{W} / \mathrm{C}$ ratio $=0.45$ & & \\
\hline
\end{tabular}

\section{Chemical Components}

Cement (Type 11)

Silicon dioxide (min.\%)

20.0

Aluminum oxide (max.\%)

6.0

Ferric oxide (max.\%)

6.0

Magnesium oxide (max.\%)

6.0

Sulfur trioxide (max.\%)

-

When $\mathrm{C}_{3} \mathrm{~A}$ is $8 \%$ or less

3.0

When $\mathrm{C}_{3} \mathrm{~A}$ is more than $8 \%$

Loss on ignition (max.\%)

3.0

Insoluble residue (max.\%)

0.75

\section{Aggregates}

Both fine aggregates and coarse aggregates come from the Wulfenstein pit. Other than quality and gradation, there are no requirements in the specification or in the referenced ASTM as to rock type or chemical composition (not verified).

\section{Water}

Water quality and chemistry shall conform to ASTM C94 (not verified).

\section{Admixtures}

Masters Builders Polyheed is a cementdispersing agent used as a water-reducing agent for pumpability. Liquid chemical is added at a percentage of $2 \%$. The composition is undetermined, although the Material Safety Data Sheet (MSDS) indicates the presence of triethanolamine and ammonium thiocyanate in $<10 \%$ quantities. Hazardous decomposition products include: oxides of carbon, sulfur, and nitrogen; ammonia, hydrogen sulfide, and hydrocyanic acid.

Master Builders MB QSL 100 is added as an accelerator to increase early strength. This liquid chemical is added in a percentage of 2 to $6 \%$ of cement, and contains sodium aluminate from 30 to $60 \%$. No other chemical components are listed on the MSDS. 
Two other admixtures, both of which are silica fume, were not specified for the ESF in the 501 mix.

1. Master Builders MB-SF silica fume mineral admixture is a pozzolan that reacts chemically with the concrete to increase the amount of calcium silicate hydrate gel formed, thus improving strength and permeability. It can be used in quantities of 5 to $15 \%$ of the weight of cement. Chemical components are as follows:

- Silica fume-greater than $99 \%$

- Silica dioxide-none

- Crystalline quartz-less than $1 \%$

2. Sikacrete $950 \mathrm{DP}$ is a densified dry powder microsilica admixture (amorphous silica) $\mathrm{SiO}$ (added for strength). It can be used in quantities of 5 to $15 \%$ of the weight of cement.

\section{Steel Sets}

Steel sets include steel lagging, steel foot plates, steel set connection, shim plates, steel wedges, and miscellaneous steel. Steel set size is W8 $\times 31,25$-ft diam.

Reference: ASTM A36 (bolts and nuts come under ASTM A370 \& A563).

Specification: BABEE0000-01717-6300-02341

Rev 002.

Materials for steel sets will be tested for strength, ductility, and chemical composition. Tensile and yield will be tested according to ASTM A370 Sec. 13 and ASTM A370 Sec. 14, respectively. Chemical analysis will be done according to ASTM A751 and E30. Chemical requirements of ASTM A36 steel is as follows (actual steel sets 12/18/94):

\begin{tabular}{|c|c|c|c|}
\hline Product & Shapes* & $\begin{array}{l}\text { Test } \\
133\end{array}$ & $\begin{array}{c}\text { Test } \\
168\end{array}$ \\
\hline Carbon (max.\%) & 0.26 & 0.07 & 0.07 \\
\hline Manganese (\%) & - & - & - \\
\hline $\begin{array}{l}\text { Phosphorus } \\
\text { (max.\%) }\end{array}$ & 0.04 & 0.021 & 0.025 \\
\hline Sulfur (max. \%) & 0.05 & 0.029 & 0.031 \\
\hline Silicon (max. \%) & 0.40 & 0.14 & 0.12 \\
\hline $\begin{array}{l}\text { Copper (min.\% } \\
\text { when copper } \\
\text { steel is specified) }\end{array}$ & 0.20 & & \\
\hline
\end{tabular}

1. Manganese content of $0.85-1.35 \%$ and silicon content of $0.15-0.40 \%$ are required for shapes over $426 \mathrm{lb} / \mathrm{ft}$.

2. For each reduction of $0.01 \%$ below the specified carbon maximum, an increase of $0.06 \%$ manganese above the specified maximum will be permitted up to the maximum of $1.35 \%$.

3. When zinc-coated (galvanized), zinc is added to metal on the basis of oz. $/ \mathrm{ft}^{2}$ (ASTM A390).

4. When an alloy is specified, an example of typical composition is as follows (from ASTM E1282):

\begin{tabular}{lll}
\hline \multicolumn{1}{c}{ Element } & \multicolumn{1}{c}{ Alloy A } & \multicolumn{1}{c}{ Alloy B } \\
\hline Carbon (\%) & $0.15-0.35$ & $0.40-0.80$ \\
Manganese (max.\%) & 1.1 & 1.4 \\
Chromium (\%) & $19.5-29.0$ & $32.0-38.5$ \\
Iron (\%) & 24 min. & balance \\
$\begin{array}{l}\text { Copper + vanadium } \\
\text { (\%) }\end{array}$ & 0.03 max. & 0.45 min. \\
Oxygen (ppm max.) & 30 & 55 \\
Aluminum (\%) & $0.01-0.11$ & $0.19-0.31$ \\
\hline
\end{tabular}


The aluminum concentration requirement applies only to material made for high-temperature applications. Its quantitative determination is not required on material designated for other uses.

Tensile requirements of ASTM A36 steel is as follows:

\section{Plate Shapes and Bars}

Tensile strength, ksi (MPa)

Yield point min, ksi (MPa)

Plates and Bars

Elongation in 8 in. (min.\%)

Elongation in 2 in. (min.\%)

Shapes

Elongation in 8 in. (min.\%)

Elongation in 2 in. (min.\%)

$58-80(400-550)$
$36(250)$
20
23

20
21

\section{Rock Bolts}

Kiewit PB-Dana Rogers, water usage estimate/ rock bolt.

Reference: ASTM A 615, ASTM F432 (Grade 60). Specification: BABEAB00-01717-6300-02165 Rev. 06.

Rock bolts shall be \#8 solid deformed bar complying with ASTM A615 grade 60 and ASTM F432. "Hollow core rock bolts shall be hollow, all thread bar complying with ASTM A615 grade 60 or stronger, such as Williams hollow core bar B7X 1-1/8 in. diam, manufactured according to ASTM F432."

Substitution of rock bolts and accessories meeting standards different from those specified is allowable provided the items meet the following criteria:

- Must be of equal or better quality.

- Must be recommended by the manufacturer for the intended use.

- Shall be approved by the Architect/Engineer (AE). The Super Swellex, standard Swellex, and Split Set Proprietary systems are indicated to be acceptable to the Engineer.

\section{Chemical Composition}

From ASTM F432, the chemical composition is as follows (Note: The maximum percentage of manganese is not listed in this source):

\begin{tabular}{lccc}
\hline & $\begin{array}{c}\text { Carbon } \\
\text { max. } \\
(\%)\end{array}$ & $\begin{array}{c}\text { Sulfur } \\
\text { max. } \\
(\%)\end{array}$ & $\begin{array}{c}\text { Phos- } \\
\text { phorus } \\
\text { max. (\%) }\end{array}$ \\
\hline Rock bolts & 0.79 & & 0.058 \\
Wedges & 0.84 & & 0.058 \\
Washers & 0.84 & 0.058 & 0.058 \\
Plates & 1.04 & 0.058 & 0.058 \\
Plugs & 0.64 & - & 0.058 \\
$\begin{array}{l}\text { Steel } \\
\text { expansion } \\
\text { shells }\end{array}$ & 0.33 & 0.058 & 0.058 \\
\hline
\end{tabular}

From North Ramp Ground Support Scoping Analysis, the chemical composition of rock bolts and accessories is as follows:

$\begin{array}{ll}\text { Carbon max. (\%) } & 0.79 \\ \text { Sulfur max. (\%) } & 0.050 \\ \text { Phosphorus max. (\%) } & 0.058 \\ \text { Manganese max. (\%) } & 1.0 \\ \text { Mechanical Properties of Steel Bars } \\ \text { for Rock Bolts }\end{array}$

From ASTM 432, the mechanical properties of steel bars for rock bolts are as follows. [Note: ASTM A615 requires the same values.]

Grade

60

Diameter

$5 / 8$ to $1-1 / 2$

psi (MPa)

$60,000(414)$

psi (MPa)

$90,000(621)$

$200 \mathrm{~mm}$ (min\%)

9

Williams Rockbolts (advantage quick set + grant for long life or + resins (epoxy) (leave the expander in hole).

\section{Hollow-Core All-Thread (B7X) Structural Properties}

Yield stress (ksi)

91

Ultimate stress (ksi)

12

Elongation (\%)

$15 \%$ in 2 in 
Mechanical properties of steel bars for rock bolts (from Williams Catalog No. 392, p. 8).

$\begin{array}{ll}\text { Diameter } & 1-1 / 8 \\ \text { Maximum outside diameter } & 1-3 / 16 \\ \text { Inside diameter } & 0.325 \\ \text { Net area } & 0.68 \\ \text { Working load (lb) } & 40,000 \\ \text { Yield strength } & 60,000 \\ \text { Ultimate strength } & 80,000\end{array}$

Chemical properties on certificate of test (from Williams) of 4/11/95 are as follows:

$\begin{array}{ll}\text { Carbon } & 0.38 \\ \text { Manganese } & 1.33 \\ \text { Phosphorus } & 0.013 \\ \text { Sulfur } & 0.018 \\ \text { Silicon } & 0.28\end{array}$

Aluminum

0.002

Split set rock bolts

(grout required?)

Mechanical properties of Split Set Stabilizer system (from Split Set Catalog of Ingersoll-Rand Co).

\begin{tabular}{lccc}
\hline $\begin{array}{l}\text { Stabilizer } \\
\text { model }\end{array}$ & SS-33 & SS-39 & SS-46 \\
\hline $\begin{array}{l}\text { Split set tube } \\
\text { length* (ft) }\end{array}$ & $3-8$ & $3-10$ & $3-12$ \\
$\begin{array}{l}\text { Breaking } \\
\text { capacity (tons) }\end{array}$ & $8-12$ & $10-14$ & $15-20$ \\
$\begin{array}{l}\text { Recommended } \\
\text { initial }\end{array}$ & $3-6$ & $3-6$ & $6-10$ \\
$\begin{array}{l}\text { anchorage } \\
\text { (tons) }\end{array}$ & & & \\
Domed bearing plate: $10-$ to 15-ton capacity \\
\hline
\end{tabular}

*Note: "Split set stabilizers are manufactured in accordance with specifications of ASTM 432." Available in standard or galvanized. Chemical composition of this product is not yet available.

\section{Standard Swellex/Super Swellex}

Mechanical properties of Swellex rock-bolt system (from Swellex Catalog of Atlas Copco Co.).

\begin{tabular}{lcc}
\hline $\begin{array}{l}\text { Mechanical } \\
\text { property }\end{array}$ & $\begin{array}{c}\text { Standard } \\
\text { Swellex }\end{array}$ & $\begin{array}{c}\text { Super } \\
\text { Swellex }\end{array}$ \\
\hline Length (ft) & $4-12$ & $10-20$ \\
$\begin{array}{l}\text { Breaking load } \\
\text { (tons) }\end{array}$ & $11-12$ & $22-24$ \\
$\begin{array}{l}\text { Minimum } \\
\text { elongation (\%) }\end{array}$ & 15 & 15 \\
$\begin{array}{l}\text { Original tube } \\
\text { dimension (in.) }\end{array}$ & $1-5 / 8 \times 5 / 64$ & $2-1 / 8 \times 1 / 8$ \\
$\begin{array}{l}\text { Water pressure } \\
\text { (psi) }\end{array}$ & 4300 & 4300 \\
\hline
\end{tabular}

Chemical composition of this product as reported 6/21/95 is as follows:

\begin{tabular}{lll}
\hline & \multicolumn{2}{c}{ Test } \\
\cline { 2 - 3 } Chemical & $\mathbf{2 3 - 3 0 6 4}$ & $\mathbf{6 4 - 1 9 2 4}$ \\
\hline Carbon & 0.07 & 0.08 \\
Manganese & 0.62 & 0.67 \\
Phosphorus & 0.12 & 0.006 \\
Sulfur & 0.011 & 0.011 \\
Aluminum & 0.004 & 0.003 \\
Silicon & 0.00 & 0.01 \\
\hline
\end{tabular}




\section{Grout for Rock Bolts}

Reference: ASTM C845 Standard Specification for Expansive Hydraulic Cement.

Specification: rock bolts and accessories, BABEAB000-01717-6300-02165 Rev 06, Type K cement.

Thixotropic Grout: A thick cementitious grout that is pumpable as a fluid and will increase in apparent viscosity upon standing and thus will prevent the grout from migrating from the borehole after installation; as a result no special packers are required.

\section{Chemical Composition}

From Certificate of Certification from Southwest Portland Cement Co.

Silicon dioxide $(\mathrm{SiO}) \quad 18.70$

Aluminum oxide $\left(\mathrm{A}_{2} \mathrm{O}_{3}\right) \quad 5.5$

Ferric oxide $\left(\mathrm{FO}_{3}\right) \quad 2.9$

Magnesium oxide (MgO) $\quad 4.0$

Sulfur trioxide $\left(\mathrm{SO}_{3}\right) \quad 5.4$

Loss on ignition $\quad 1.9$

Insoluble residue $\quad 0.3$

Compressive Strength (psi)

1 day

1500-2000

3 days

$3000-1000$

7 days

4000-5000

28 days 


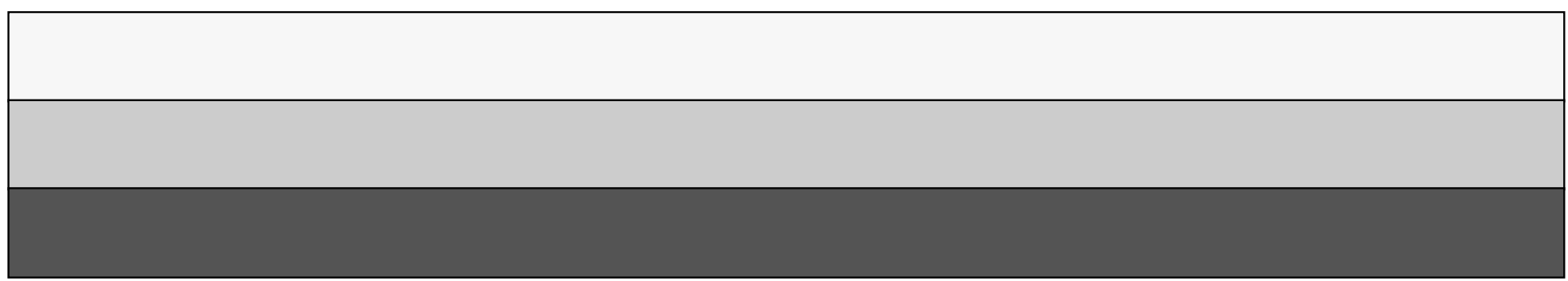

